\title{
Modeling and dynamic analysis of spiral bevel gear coupled system of intermediate and tail gearboxes in a helicopter.
}

\author{
ZHU, H., CHEN, W., ZHU, R., ZHANG, L., FU, B. and LU, X.
}

ZHU, H., CHEN, W., ZHU, R., ZHANG, L., FU, B. and LU, X. 2021. Modeling and dynamic analysis of spiral bevel gear coupled system of intermediate and tail gearboxes in a helicopter. Proceedings of the Institution of Mechanical Engineers, part C: journal of mechanical engineering science [online], 235(22), pages 5975-5993. Copyright (c) 2021 IMechE. DOI: 10.1177/0954406221992798.

Users who receive access to an article through a repository are reminded that the article is protected by copyright and reuse is restricted to non-commercial and no derivative uses. Users may also download and save a local copy of an article accessed in an institutional repository for the user's personal reference. For permission to reuse an article, please follow our Process for Requesting Permission. 


\title{
Modeling and dynamic analysis of spiral bevel gear coupled system of intermediate and tail gearboxes in a helicopter
}

\author{
Haimin Zhu' ${ }^{1}$, Weifang Chen ${ }^{1, *}$, Rupeng Zhu', Li Zhang ${ }^{2}$, Bibo Fu ${ }^{3}$, Xiong Lu ${ }^{3}$ \\ 1. National Key Laboratory of Science and Technology on Helicopter Transmission, Nanjing \\ University of Aeronautics and Astronautics, Nanjing, 210016, China; \\ Email: meewfchen@nuaa.edu.cn \\ 2. National Subsea Centre, Robert Gordon University, Aberdeen, AB10 7GJ, UK; \\ 3. AECC Hunan Aviation Powerplant Research Institute, Zhuzhou, 412000, China
}

\begin{abstract}
The coupled dynamic model of the intermediate and tail gearboxes' spiral bevel gear-oblique tail shaft-laminated membrane coupling was established by employing the hybrid modeling method of finite element and lumped mass. Among them, the dynamic equation of the shaft was constructed by Timoshenko beam; spiral bevel gears were derived theoretically by the lumped-mass method, where the effects of time-varying meshing stiffness, transmission error, external imbalance excitation and the like were considered simultaneously; laminated membrane coupling was simplified to a lumped parameter model, in which the stiffness was obtained by the finite element simulation and experiment. On this basis, the laminated membrane coupling and effects of several important parameters, including the unbalance value, tail rotor excitation, oblique tail shaft's length and transmission error amplitude, on the system's dynamic characteristics were discussed. The results showed that the influences of laminated membrane coupling and transmission error amplitude on the coupled system's vibration response were prominent, which should be taken into consideration in the dynamic model. Due to the bending-torsional coupled effect, the lateral vibration caused by gear eccentricity would enlarge the oblique tail shaft's torsional vibration; similarly, the tail rotor's torsional excitation also varies the lateral vibration of the oblique tail shaft. The coupled effect between the eccentricity of gear pairs mainly hit the torsional vibration. Also, as the oblique tail shaft's length increased, the torsional vibration of the oblique tail shaft tended to diminish while the axis orbit became larger. The research provides theoretical support for the design of the helicopter tail transmission system.
\end{abstract}

Keywords- Spiral bevel gear Oblique tail shaft Finite element method Lumped mass method Tail rotor excitation

\section{Introduction}

The helicopter tail transmission system involves an angular spiral bevel gear pair and an orthogonal spiral bevel gear pair, and the two gear pairs are connected by a long thin-walled oblique tail shaft. Therefore, the vibration response from each part is no longer independent but coupled with each other. Moreover, the tail transmission system is not only excited by two spiral bevel gear pairs, but also by external excitation such as unbalanced force and tail rotor force, which lead to complex dynamic characteristics. To provide more theoretical guidance for the helicopter tail transmission system, it is vital to investigate the coupled vibration of the spiral bevel geared rotor system.

Currently, there were many investigations on the single-pair geared rotor transmission system, mainly focusing on the modeling method and dynamic characteristics. Geared rotor transmission 
system's modeling methods involved finite element method, centralized mass method, and transfer matrix method. Wang [1] and Fan [2] formulated the bending-torsional coupled models of spiral bevel gears and planetary gears by the lumped-mass method, respectively. Based on the transfer matrix method, Choi [3] and fan [4] analyzed the vibration response of the geared rotor transmission system. Neriya et al. [5] simulated the geared rotor system's bending-torsional coupled vibration by the finite element method. This method was used extensively by scholars because it could simulate the effect of multiple factors such as elastic shaft and bearing parameters [6-9]. Similarly, Li [10] and Yavuz [11] utilized the finite element method to study the dynamic properties of the coupled system with spiral bevel gears. Zhu et al. [12] established the dynamic model of a single-stage spiral bevel gear system by the hybrid method of finite element and lumped mass, where the influences of transmission error, shaft flexibility, and gearbox flexibility were considered. Then, the effects of key parameters on the coupled system's dynamic characteristics were analyzed.

Based on the single-pair geared rotor transmission system, the relevant studied on the multipair geared rotor system were carried out by various scholars. Wang [13] employed the finite element method to derive a coupled dynamic model of the two-stage helical gear system, and the effect of eccentricity and other key parameters on the system's dynamic response was investigated. Jian and Parker [14] investigated the influence of meshing stiffness on the multi-stage parallel-shaft gear transmission system's vibration response, involving the effect of meshing frequency, meshing phase and other unstable factors. Al-shhyab and Kahraman [15] proposed a nonlinear dynamic model of a multi-stage spur geared rotor system. In their work, the effects of key parameters such as meshing stiffness, meshing damping and torque on the subharmonic motion were discussed. Walha et al. [16] demonstrated 12 degrees of freedom dynamic equations of a two-stage spur gearpair, which solved by the Newmark iteration method, and found that the root of nonlinear vibration was the contact loss between gear teeth. Rao et al. [17] discussed the two-stage gear transmission system's dynamic characteristics, considering the intermediate shaft's stiffness, where the system's nonlinear stability was investigated through the multi-scale method. Yassine [18] and Li [19] studied the dynamic models of multi-stage straight bevel gear and parallel-shaft gear system, respectively. According to Timoshenko beam theory and the Lagrange equation, Tan et al [20] put forward a dynamic modeling method, in which some important effects such as main shaft's flexibility and suspension structure were taken into account. Lin et al. [21] discussed the vibration response of multi-stage planetary gear reducer by the centralized parameter method, and the dynamic equation was solved by the Runge Kutta method. Liu et al. [22] deduced a new discrete elastic model of planetary gears, which considered sliding friction and elastic continuous ring gear. Then, the impact of sliding friction on the meshing stiffness was discussed. Yan et al. [23] developed a two-stage geared rotor system's dynamic model through the finite element method, where the meshing stiffness and clearance were obtained through the tooth surface contact analysis. Mo et al. [24-26] employed the centralized parameter method to establish the translational-torsional dynamic equations of herringbone planetary gear train and multi-power face gear split-flow system, respectively, then the effects of some key factors on the load-sharing characteristic were studied. The above analysis of the multi-stage geared rotor transmission system provided a lot of valuable references for the dynamic design of the complex gear system. However, the connecting shaft between gear pairs was short. Meanwhile, the current study of the multi-stage gear transmission system was mainly aimed at the parallel-shaft gear transmission system, and there is little research on the multi-pair spiral bevel geared rotor system. Therefore, based on the structural characteristics 
of the helicopter tail transmission system, this paper comprehensively proposed a dynamic model of coupled transmission system involving spiral bevel gears of intermediate and tail gearboxes, oblique tail shaft, and laminated membrane coupling.

The main contents of the remaining parts of this paper were organized as follows: firstly, the spiral bevel gear coupled system of the intermediate and tail gearboxes in a helicopter tail transmission system was chosen as the research object, and its mechanical model was established. Then, the transmission shaft's dynamic equation and meshing element's stiffness and damping matrix were established by the finite element and lumped-mass method, respectively. After that, combined with the stiffness matrix of laminated membrane coupling and the ball bearing's stiffness and damping matrix, the dynamic model of the coupled system was proposed. On this basis, the dynamic equations were solved by the Newmark numerical algorithm, and the effects of laminated membrane coupling, unbalance value, tail rotor excitation, length of the oblique tail shaft and transmission error amplitude on the system's dynamic properties were discussed in detail.

\section{Mechanical model of the coupled system}

Fig. 1 exhibited the coupled system's three-dimensional model, mainly consisting of angular spiral bevel gear-pair, orthogonal spiral bevel gear-pair, oblique tail shaft and laminated membrane coupling. Also, the coordinate system $\mathrm{O}-\mathrm{XYZ}$ was the global coordinate system of the whole prototype, and the coordinate systems $\mathrm{O}_{1}-\mathrm{X}_{1} \mathrm{Y}_{1} \mathrm{Z}_{1}, \mathrm{O}_{2}-\mathrm{X}_{2} \mathrm{Y}_{2} \mathrm{Z}_{2}$ and $\mathrm{O}_{3}-\mathrm{X}_{3} \mathrm{Y}_{3} \mathrm{Z}_{3}$ were the local coordinate systems of the input shaft, oblique tail shaft and output shaft, respectively, wherein the local coordinate system of input shaft was consistent with the global coordinate system.

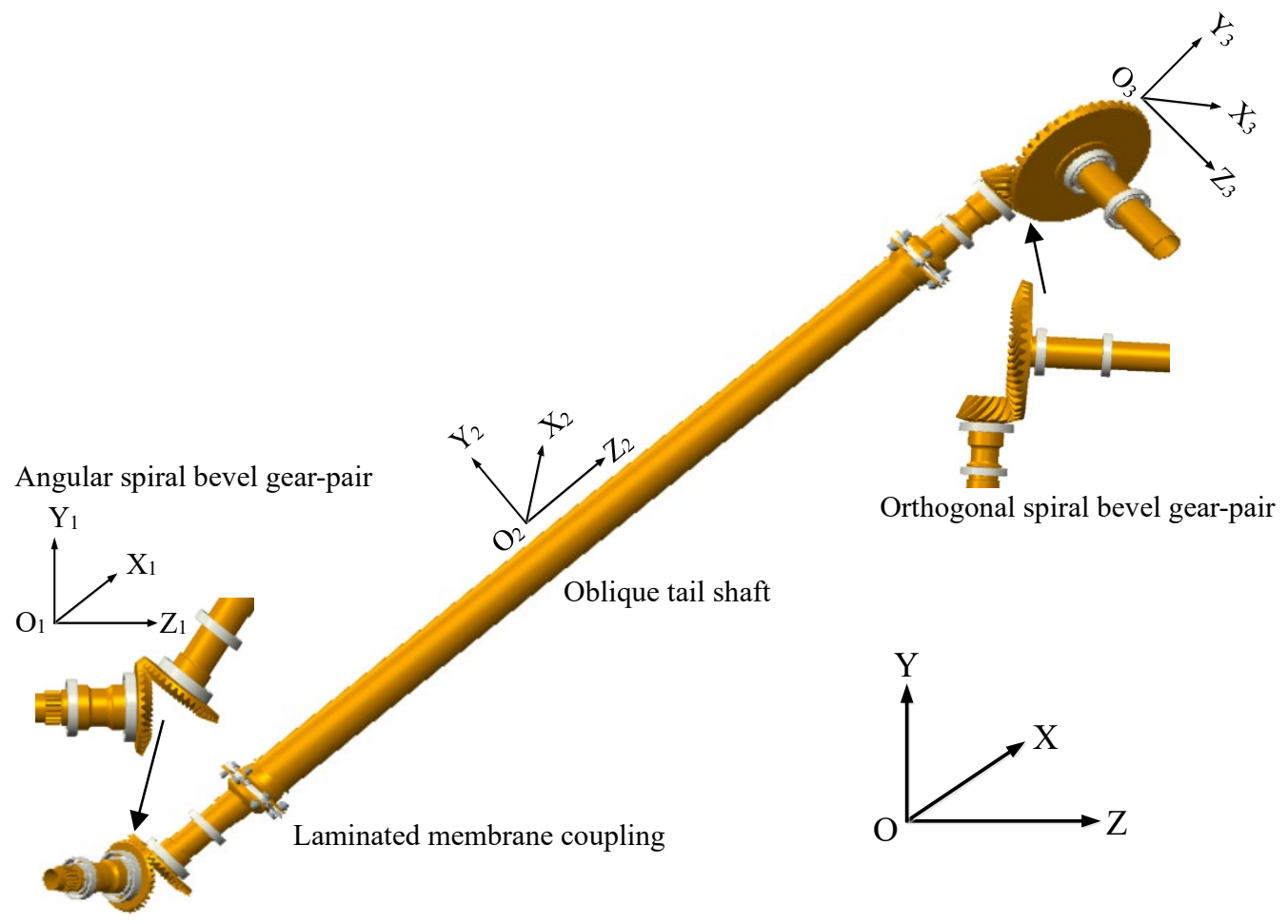

Fig. 1 The 3D model of the coupled system

Timoshenko beam element was utilized to discrete the hollow thin-walled rotor, and the finite element dynamic equations of each shaft were created, and Spiral bevel gear-pairs were equivalent to lumped parameter models. Meanwhile, Laminated membrane couplings were simplified as 
lumped parameter models, whose stiffness matrix was concentrated on the corresponding nodes of the beam element connected with the lamination group, respectively. Moreover, it was essential to transform the elements in the local coordinate system into the global coordinate system by way of the spatial coordinate transformation due to the diverse directions of the local coordinate system of shafts and gear pairs in the system, and then the parameters of each element could be described in the global coordinate system. Based on it, the finite element mechanical model of the coupled system of the intermediate and tail gearboxes was established in the global coordinate system, as demonstrated in Fig. 2. Nodes 1-5 and 6-9 correspond to the input and output shaft beam element of the first gear-pair, respectively; nodes 10-16 correspond to the oblique tail shaft beam elements; nodes 17-20 and 21-27 correspond to the input and output shaft beam element of the second gearpair, respectively. Besides, nodes 5 and 6 , nodes 20 and 21 were coupled with each other through the first and second meshing unit; nodes 9 and 10, nodes 16 and 17 were affected with each other through laminated membrane couplings.

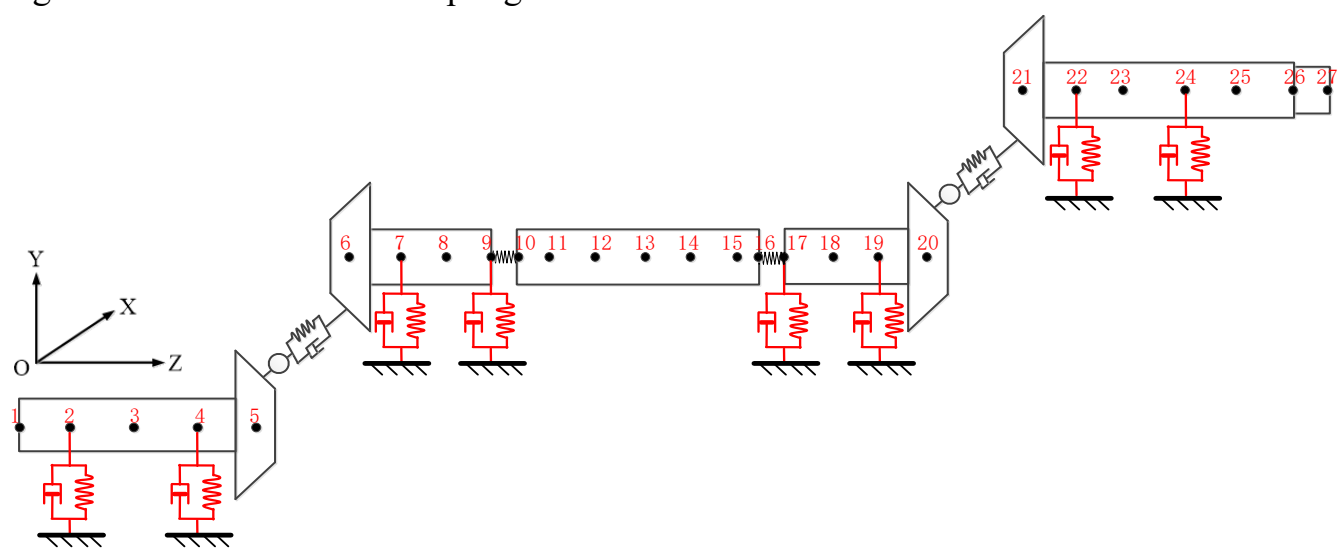

Fig. 2 The finite element mechanical model of the coupled system

\section{Dynamic modeling of the coupled system}

\subsection{Thin-walled shaft modeling}

Since the bending-torsional-axial-swing coupled vibration was taken into account in spiral bevel gears, Timoshenko beam element with 12 degrees of freedom was employed to divide each shaft, which could be expressed as $\mathbf{X}_{e}=\left[x_{i}, y_{i}, z_{i}, \theta_{x i}, \theta_{y i}, \theta_{z i}, x_{i+1}, y_{i+1}, z_{i+1}, \theta_{x(i+1)}, \theta_{y(i+1)}, \theta_{z(i+1)}\right]^{T}$.

According to existing studies [27-28], the mass matrix $\mathbf{M}_{e}$, stiffness matrix $\mathbf{K}_{e}$, damping matrix $\mathbf{C}_{e}$ and gyro matrix $\mathbf{G}_{e}$ of the beam element could be obtained, respectively. It could be known that the beam element's characteristic matrix should be described in the global coordinate system by the spatial coordinate transformation when building the overall matrix of the system. The relationship between the ith beam element's vibration displacement in the local coordinate system and that in the global coordinate system could be written as

$$
\left.\left[x_{i}{ }^{\prime}, y_{i}{ }^{\prime}, z_{i}^{\prime}, \theta_{x_{i}}{ }^{\prime}, \theta_{y_{i}}{ }^{\prime}, \theta_{z_{i}}{ }^{\prime}, x_{i+1}{ }^{\prime}, y_{i+1}{ }^{\prime}, z_{i+1}{ }^{\prime}, \theta_{x(i+1)}{ }^{\prime}, \theta_{y(i+1)}{ }^{\prime}, \theta_{z(i+1)}\right]^{\prime}\right]^{T}=\lambda\left[x_{i}, y_{i}, z_{i}, \theta_{x_{i}}, \theta_{y_{i}}, \theta_{z_{i}}, x_{i+1}, y_{i+1}, z_{i+1}, \theta_{x(i+1)}, \theta_{y(i+1)}, \theta_{z(i+1)}\right]^{T}(1)
$$

Here $\lambda=\operatorname{diag}(\boldsymbol{T}, \boldsymbol{T}, \boldsymbol{T}, \boldsymbol{T}) ; \boldsymbol{T}=\boldsymbol{T}_{z} \boldsymbol{T}_{y} \boldsymbol{T}_{x} ;$

and

$$
\boldsymbol{T}_{x}=\left[\begin{array}{ccc}
1 & 0 & 0 \\
0 & \cos \varphi_{x} & \sin \varphi_{x} \\
0 & -\sin \varphi_{x} & \cos \varphi_{x}
\end{array}\right], \boldsymbol{T}_{y}=\left[\begin{array}{ccc}
\cos \varphi_{y} & 0 & \sin \varphi_{y} \\
0 & 1 & 0 \\
-\sin \varphi_{y} & 0 & \cos \varphi_{y}
\end{array}\right], \boldsymbol{T}_{z}=\left[\begin{array}{ccc}
\cos \varphi_{z} & \sin \varphi_{z} & 0 \\
-\sin \varphi_{z} & \cos \varphi_{z} & 0 \\
0 & 0 & 1
\end{array}\right]
$$


where $\varphi_{x}, \varphi_{y}$ and $\varphi_{z}$ are the rotation angle around $X, Y$ and $Z$ in the global coordinate system, respectively.

Then, the mass matrix, stiffness matrix, damping matrix, gyro matrix and force vector of the ith beam element in the global coordinate system could be displayed as below [29].

$$
\mathbf{M}_{i}^{\prime}=\lambda^{T} \mathbf{M}_{i} \lambda, \quad \mathbf{K}_{i}^{\prime}=\lambda^{T} \mathbf{K}_{i} \lambda, \mathbf{C}_{i}^{\prime}=\lambda^{T} \mathbf{C}_{i} \lambda, \mathbf{G}_{i}^{\prime}=\lambda^{T} \mathbf{G}_{i} \lambda, \mathbf{F}_{i}^{\prime}=\lambda^{T} \mathbf{F}_{i}
$$

By combining Figs. 1 and 2, the coordinate transformation matrix $\lambda_{1}, \lambda_{2}$ and $\lambda_{3}$ of nodes 1-5, 6-20 and 21-27 were obtained so as to convert the local coordinates of all beam nodes to the global coordinate system, which could be shown as

$$
\begin{gathered}
\lambda_{1}=\operatorname{diag}\left(\boldsymbol{T}_{1}, \boldsymbol{T}_{1}, \boldsymbol{T}_{1}, \boldsymbol{T}_{1}\right) ; \boldsymbol{T}_{1}=\boldsymbol{T}_{\gamma=0} \boldsymbol{T}_{\beta=0} \boldsymbol{T}_{\alpha=0} \\
\boldsymbol{\lambda}_{2}=\operatorname{diag}\left(\boldsymbol{T}_{2}, \boldsymbol{T}_{2}, \boldsymbol{T}_{2}, \boldsymbol{T}_{2}\right) ; \boldsymbol{T}_{2}=\boldsymbol{T}_{\gamma=0} \boldsymbol{T}_{\beta=0} \boldsymbol{T}_{\alpha=-\left(\pi-\theta_{1} \cdot p i / 180\right)} \\
\boldsymbol{\lambda}_{3}=\operatorname{diag}\left(\boldsymbol{T}_{3}, \boldsymbol{T}_{3}, \boldsymbol{T}_{3}, \boldsymbol{T}_{3}\right) ; \boldsymbol{T}_{3}=\boldsymbol{T}_{\gamma=0} \boldsymbol{T}_{\beta=-\theta_{2} \cdot p i / 180} \boldsymbol{T}_{\alpha=-\left(\pi-\theta_{1} \cdot p i / 180\right)}
\end{gathered}
$$

According to the finite element theory, the differential equations of the $r t h(r=1,2,3,4,5)$ shaft was obtained, which could be expressed as

$$
\mathbf{M}_{r} \ddot{\mathbf{X}}_{r}+\left(\mathbf{C}_{r}-\omega_{r} \mathbf{G}_{r}\right) \dot{\mathbf{X}}_{r}+\mathbf{K}_{r} \mathbf{X}_{r}=\mathbf{F}_{r}
$$

where $\mathbf{M}_{r}, \mathbf{C}_{r}, \mathbf{G}_{r}$ and $\mathbf{K}_{r}$ are the mass, damping, gyro and stiffness matrices of the $r$ th shaft, respectively; $\mathbf{F}_{r}$ and $\omega_{r}$ represent the load vector and angular velocity of the $r$ th shaft, respectively; $\ddot{\mathbf{X}}_{r}, \dot{\mathbf{X}}_{r}$ and $\mathbf{X}_{r}$ are the $r$ th shaft's acceleration, velocity and displacement vectors, respectively.

\subsection{Modeling of spiral bevel gear}

\subsubsection{Calculation of time-varying meshing stiffness}

Stiffness excitation is the main excitations of the geared rotor system vibration. For spiral bevel gears, it is tricky to achieve the accurate meshing stiffness because of the complicated tooth surfaces. Consequently, the spiral bevel gear pair's time-varying stiffness was solved accurately through ANSYS finite element analysis in the study [12], where the spiral bevel gear pairs' main parameters were exhibited in Table 1. According to the reduction ratio between the spiral bevel gears, the load torque of the first one is $102.44 \mathrm{Nm}$ when the load torque of the second spiral bevel gear pair is $\mathrm{T}=300 \mathrm{Nm}$. Under this condition, the two spiral bevel gear pairs' comprehensive meshing stiffnesses were calculated, respectively, as shown in Fig. 3. 
Table 1 Main design parameters of spiral gear pairs

\begin{tabular}{ccc}
\hline Parameter & First gear-pair & Second gear-pair \\
\hline Young's modulus (MPa) & $E_{1}=2.068 \mathrm{e} 5$ & $E_{2}=2.068 \mathrm{e} 5$ \\
Poisson's ratio & $v_{1}=0.29$ & $v_{2}=0.29$ \\
Pressure angle $\left(^{\circ}\right)$ & $\alpha_{1}=20$ & $\alpha_{2}=20$ \\
Spiral angle $\left(^{\circ}\right)$ & $\beta_{1}=35$ & $\beta_{2}=35$ \\
Module (m) & $m_{1}=5.6 \mathrm{e}-3$ & $\mathrm{~m}_{2}=7.98 \mathrm{e}-3$ \\
Teeth width (m) & $\mathrm{B}_{1}=3.3 \mathrm{e}-2$ & $\mathrm{~B}_{2}=5.7 \mathrm{e}-2$ \\
Teeth number of the pinion & $N_{p 1}=29$ & $N_{p 2}=14$ \\
Teeth number of the gear & $N_{g 1}=35$ & $N_{g 2}=41$ \\
Shaft angle $\left({ }^{\circ}\right)$ & $\theta_{1}=126$ & $\theta_{2}=90$ \\
Transmission error mean $(\mathrm{m})$ & $e_{m 1}=1 \mathrm{e}-5$ & $e_{m 2}=1 \mathrm{e}-5$ \\
\hline Transmission error amplitude $(\mathrm{m})$ & $e_{r 1}=5 \mathrm{e}-6$ & $e_{r 2}=5 \mathrm{e}-6$ \\
\hline
\end{tabular}

The comprehensive time-varying stiffness was transformed into a Fourier series, which could be displayed as follows.

$$
k_{h}(t)=A_{0}+\sum_{i=1}^{N}\left[A_{i} \cos \left(i \Omega_{h} t\right)+B_{i} \sin \left(i \Omega_{h} t\right)\right]
$$

Here $A_{0}$ and $N$ are the meshing stiffness's average value and the order of the Fourier series, and $N=6 ; A_{i}$ and $B_{i}$ are the $i t h$ harmonic amplitudes of the meshing stiffness; $\Omega_{h}$ denotes the meshing circle frequency.

Fig. 4 depicted the Fourier series curve of the meshing stiffness of the two gear pairs. Among them, the meshing stiffness curves' specific parameters were shown in Table 2.

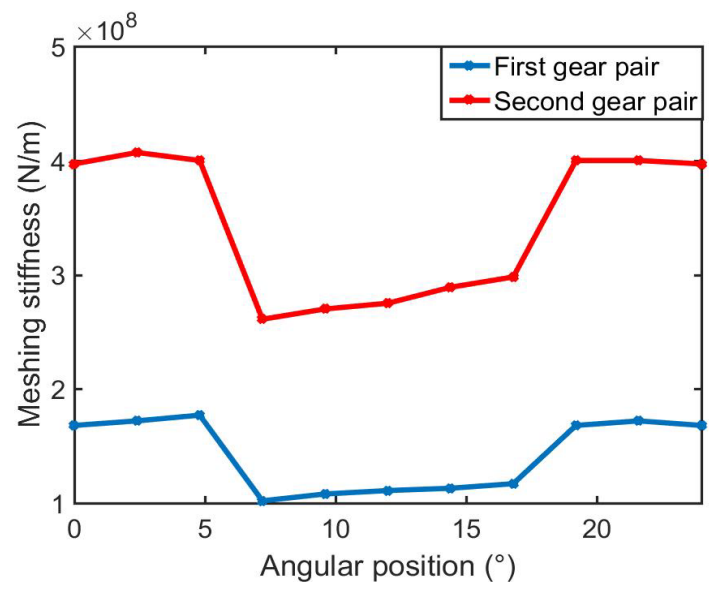

Fig. 3 The curve of time-varying meshing stiffness

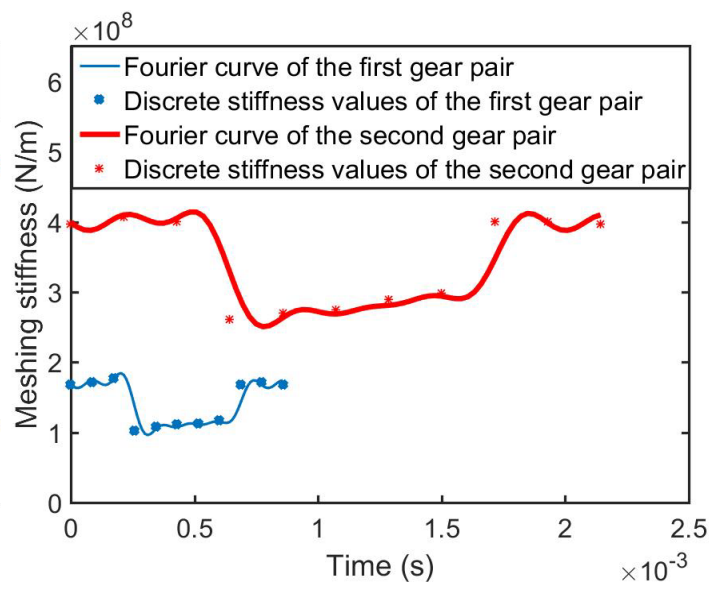

Fig. 4 Fourier series form of meshing stiffness 
Table 2 The value of the Fourier series of the meshing stiffness

\begin{tabular}{ccccc}
\hline & \multicolumn{2}{c}{ First gear-pair } & \multicolumn{2}{c}{ Second gear-pair } \\
\cline { 2 - 5 } & $A_{i}$ & $B_{i}$ & $A_{i}$ & $B_{i}$ \\
\hline 0 & $1.38 \mathrm{e} 8$ & $/$ & $3.32 \mathrm{e} 8$ & $/$ \\
1 & 30202549 & 22834929 & 65580492 & 42172424 \\
2 & -2993967 & 7080456 & -5388366 & 13972822 \\
3 & 4134967 & -11618311 & 6615947 & -20371833 \\
4 & 6872001 & -535227 & 12543190 & -3324939 \\
5 & -5497601 & -428182 & -10034552 & -2659954 \\
6 & -2067483 & -5809155 & -3307973 & -10185916 \\
\hline
\end{tabular}

\subsubsection{Modeling of meshing unit}

The spiral bevel gear pair's bending-torsional-axial-swing coupled dynamic model was established by the concentrated mass method, which ignores the effects of tooth surface friction, backlash and impact excitation. Then, 12 degrees of freedom of the meshing unit could be obtained, i.e., $\left[x_{p}, y_{p}, z_{p}, \theta_{p x}, \theta_{p y}, \theta_{p z}, x_{q}, y_{q}, z_{q}, \theta_{q x}, \theta_{q y}, \theta_{q z}\right]$. The dynamic modeling process of the meshing units of the first and second spiral bevel gear pairs was as follows.

1) First gear pair

The relative displacement of the spiral bevel gear pair on the meshing line could be converted into that of a pair of virtual spur gears [10]. The conversion process of the relative displacement was displayed in Fig. 5, in which the driving gear's local coordinate system was consistent with the global coordinate system, and the driving gear was assumed to rotate counterclockwise.

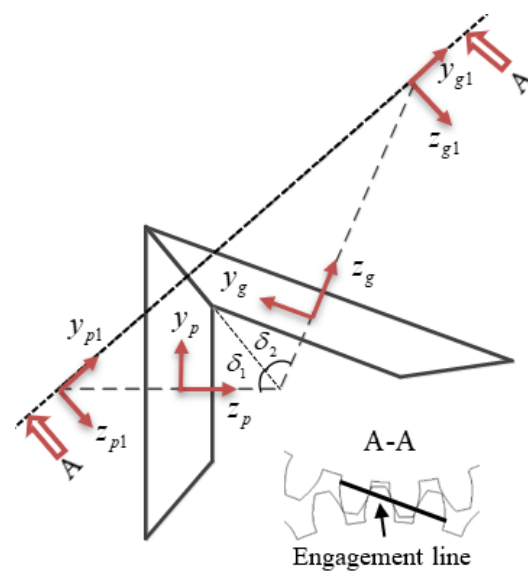

(a)

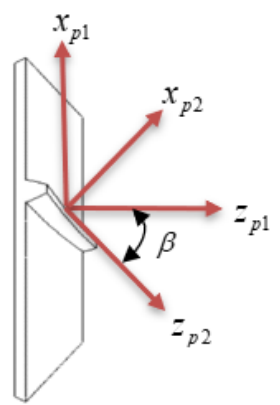

(b)

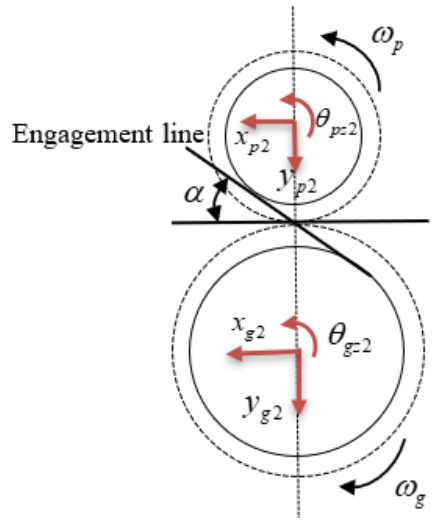

(c)

Fig. 5 The transformation process of relative displacement

The normal cosine $\mathbf{n}_{i 1}(i=p, q)$ projected from the displacement of the driving and driven gear in each direction to that of the engagement direction could be represented as [10] 


$$
\mathbf{n}_{i 1}=\left[n_{i 1 x}, n_{i 1 y}, n_{i 1 z}\right]=\mathrm{T}_{x}\left(\delta_{i 1}\right) \cdot \mathrm{T}_{\mathrm{z}}\left(\Phi_{1}\right) \cdot \mathrm{T}_{y}\left(-\psi_{i 1}\right) \cdot\left[\begin{array}{lll}
1 & 0 & 0
\end{array}\right]^{T}
$$

Here $\delta_{i 1}, \psi_{i 1}$ and $\Phi_{1}$ are the spiral bevel gear's pitch cone angle, spiral angle and pressure angle, respectively. Based on the rotation direction and the hand of the driving gear, it could be obtained that $\delta_{p 1}=\delta_{1}, \delta_{g 1}=p i-\delta_{2}, \psi_{p 1}=\beta_{1}, \psi_{g 1}=-\beta_{1}, \Phi_{1}=p i-\alpha_{1}$, where $\delta_{1}$ and $\delta_{2}$ represent the driving and driven gear's pitch cone angles, respectively.

2) Second gear pair

Similarly, Fig. 6 showed the transformation process of the second gear pair's vibration displacement to the direction of the engagement line. According to Fig. 1, there was a certain angle between the second gear pair's local coordinate system and the global coordinate system. So, the meshing stiffness matrix, damping matrix and excitation force vector should be converted to the global coordinate system.

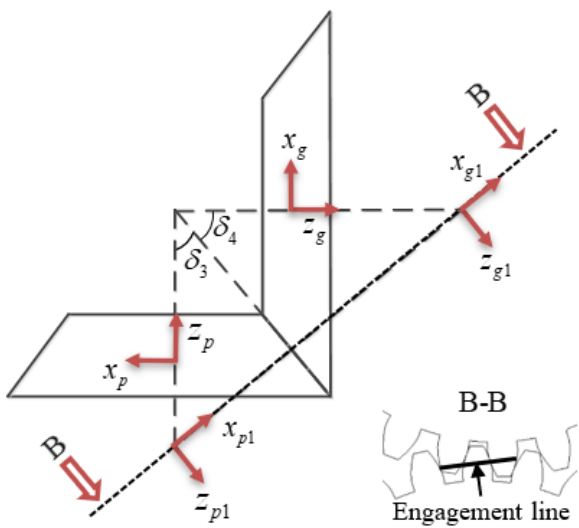

(a)

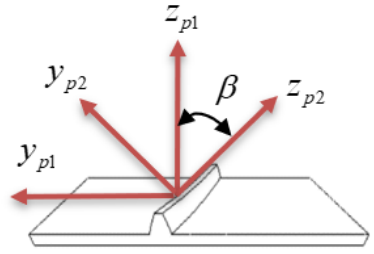

(b)

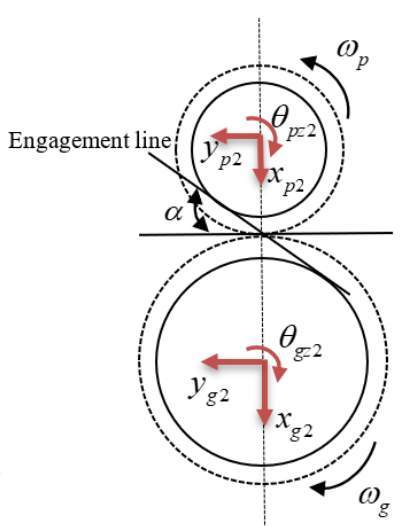

(c)

Fig. 6 The transformation process of relative displacement

The normal cosine $\mathbf{n}_{i 2}(i=p, q)$ projected from the displacement of the second gear-pair in each direction to that of the meshing direction could be expressed as [10]

$$
\mathbf{n}_{i 2}=\left[n_{i 2 x}, n_{i 2 y}, n_{i 2 z}\right]=\mathrm{T}_{y}\left(\delta_{i 2}\right) \cdot \mathrm{T}_{z}\left(\Phi_{2}\right) \cdot \mathrm{T}_{x}\left(-\psi_{i 2}\right) \cdot\left[\begin{array}{lll}
0 & 1 & 0
\end{array}\right]^{T}
$$

where $\delta_{p 2}=-\left(p i-\delta_{3}\right), \quad \delta_{g 2}=-\delta_{4}, \quad \psi_{p 2}=-\beta_{2}, \quad \psi_{g 2}=\beta_{2}, \quad \Phi_{2}=-\left(p i-\alpha_{2}\right) ; \quad \delta_{3}$ and $\delta_{4}$ denote the pitch cone angles of the driving and driven gear of the second gear-pair, respectively.

Moreover, the radius of rotation of the gear pair $j(j=1,2)$ could be acquired by

$$
\left\{\begin{array}{l}
\lambda_{i j x}=\mathbf{n}_{i j}^{T} \cdot\left(\mathbf{u}_{i x} \times \mathbf{r}_{i j}\right)=r_{i j y} n_{i j z}-r_{i j z} n_{i j y} \\
\lambda_{i j y}=\mathbf{n}_{i j}^{T} \cdot\left(\mathbf{u}_{i y} \times \mathbf{r}_{i j}\right)=r_{i j z} n_{i j x}-r_{i j x} n_{i j z} \\
\lambda_{i j z}=\mathbf{n}_{i j}^{T} \cdot\left(\mathbf{u}_{i z} \times \mathbf{r}_{i j}\right)=r_{i j x} n_{i j y}-r_{i j y} n_{i j x}
\end{array}(i=p, q \text { and } j=1,2)\right.
$$

where $\mathbf{r}_{i j}=\left[\begin{array}{lll}\mathbf{r}_{i j x} & \mathbf{r}_{i j y} & \mathbf{r}_{i j z}\end{array}\right]^{T}$ is the equivalent meshing point's position vector. According to the directions of the local coordinate systems of the driving and driven gear, the position vectors of the equivalent meshing points of the two gear pairs are $\mathbf{r}_{p 1}=\left[\begin{array}{llll}0 & r_{p 1} & 0\end{array}\right]^{T}, \mathbf{r}_{g 1}=\left[\begin{array}{lll}0 & r_{g 1} & 0\end{array}\right]^{T}$, $\mathbf{r}_{p 2}=\left[\begin{array}{lll}-r_{p 2} & 0 & 0\end{array}\right]^{T}$ and $\mathbf{r}_{g 2}=\left[\begin{array}{lll}-r_{g 2} & 0 & 0\end{array}\right]^{T}$, in which $r_{\mathrm{p} 1}, r_{\mathrm{g} 1}, r_{\mathrm{p} 2}$ and $r_{\mathrm{g} 2}$ represent the pitch circle radii of the first and second gear pairs at the midpoint of the tooth widths; $\mathbf{u}_{i x}=$ $\left[\begin{array}{lll}1 & 0 & 0\end{array}\right]^{T}, \mathbf{u}_{i y}=\left[\begin{array}{lll}0 & 1 & 0\end{array}\right]^{T}$ and $\mathbf{u}_{i z}=\left[\begin{array}{lll}0 & 0 & 1\end{array}\right]^{T}$ mean the unit vectors in the $\mathrm{X}, \mathrm{Y}$, and $\mathrm{Z}$ 
directions, respectively.

The relative displacement of the spiral bevel gear pair $j(j=1,2)$ along the normal direction of the meshing point with transmission errors could be written as

$$
\begin{aligned}
X_{n j} & =\left(x_{p j} n_{p j x}-x_{g j} n_{g j x}\right)+\left(y_{p j} n_{p j y}-y_{g j} n_{g j y}\right)+\left(z_{p j} n_{p j z}-z_{g j} n_{g j z}\right)+\left(\theta_{p j x} \lambda_{p j x}-\theta_{g j x} \lambda_{g j x}\right) \\
& +\left(\theta_{p j y} \lambda_{p j y}-\theta_{g j y} \lambda_{g j y}\right)+\left(\theta_{p j z} \lambda_{p j z}-\theta_{g j z} \lambda_{g j z}\right)-e_{n j}(t)
\end{aligned}
$$

Here $e_{n j}(t)=e_{m j}+e_{r j} \sin \left(\Omega_{j} \mathrm{t}+\phi_{j}\right) ; \Omega_{\mathrm{j}}$ and $\phi_{j}$ represent the meshing circle frequency and transmission error's initial phase angle of gear pair $j$, respectively.

Then, the relative displacement could be rewritten as

$$
X_{n j}=\mathbf{V}_{j} \mathbf{X}_{n j}-e_{n j}(t)
$$

Here $\mathbf{V}_{j}=\left[n_{p j x}, n_{p j y}, n_{p j z}, \lambda_{p j x}, \lambda_{p j y}, \lambda_{p j z},-n_{g j x},-n_{g j y},-n_{g j z},-\lambda_{g j x},-\lambda_{g j y},-\lambda_{g j z}\right]$ denotes the projection vector of the $j$ th gear pair's displacement; $\mathbf{X}_{n j}=\left[\begin{array}{ll}\mathbf{X}_{p j}^{T} & \mathbf{X}_{q j}^{T}\end{array}\right]$ is the displacement vector of the $j t h$ gear pair.

Therefore, the meshing force of the gear pair $j$ could be calculated by

$$
F_{n j}=k_{h j}(t) \mathbf{X}_{n j}+c_{m j} \dot{\mathbf{X}}_{n j}
$$

where $c_{m j}$ refers to the meshing damping of gear pair $j$, which could be given by

$$
c_{m j}=2 \xi \sqrt{k_{m j}\left(1 / m_{e p j}+1 / m_{e g j}\right)}
$$

Here $\xi$ means the meshing damping ratio, generally, in the range of 0.03 to 0.17 [30-31]. In this research, it was set to $0.07 ; k_{m j}$ denotes the stiffness of gear pair $j ; \quad m_{e p j}=I_{z p j} / r_{p j}^{2}$ and $m_{e g j}=I_{z g j} / r_{g j}^{2}$ stand for the equivalent mass of the driving and driven gears of the $j t h(j=1,2)$ gearpair, respectively.

The dynamic equations of the meshing unit $j(j=1,2)$ could be written as

$$
\left\{\begin{array}{c}
m_{p j} \ddot{x}_{p j}=F_{n j} n_{p j x}+m_{p j} e_{p j} \Omega_{p j}^{2} \cos \left(\Omega_{p j} t\right) \\
m_{p j} \ddot{y}_{p j}=F_{n j} n_{p j y}+m_{p j} e_{p j} \Omega_{p j}^{2} \sin \left(\Omega_{p j} t\right) \\
m_{p j} \ddot{z}_{p j}=F_{n j} n_{p j z} \\
I_{p j} \ddot{\theta}_{p j x}+J_{p j} \Omega_{p j} \dot{\theta}_{p j y}=F_{n j} \lambda_{p j x} \\
I_{p j} \ddot{\theta}_{p j y}-J_{p j} \Omega_{p j} \dot{\theta}_{p j x}=F_{n j} \lambda_{p j y} \\
J_{p j} \ddot{\theta}_{p j z}=F_{n j} \lambda_{p j z} \\
m_{g j} \ddot{x}_{g j}=-F_{n j} n_{p j x}+m_{g j} e_{g j} \Omega_{g j}^{2} \cos \left(\Omega_{g j} t\right) \\
m_{g j} \ddot{y}_{g j}=-F_{n j} n_{p j y}+m_{g j} e_{g j} \Omega_{g j}^{2} \sin \left(\Omega_{g j} t\right) \\
m_{g j} \ddot{z}_{g j}=-F_{n j} n_{p j z} \\
I_{g j} \ddot{\theta}_{g j x}+J_{g j} \Omega_{g j} \dot{\theta}_{g j y}=-F_{n j} \lambda_{p j x} \\
I_{g j} \ddot{\theta}_{g j y}-J_{g j} \Omega_{g j} \dot{\theta}_{g j x}=-F_{n j} \lambda_{p j y} \\
J_{g j} \ddot{\theta}_{g j z}=-F_{n j} \lambda_{p j z}
\end{array}\right.
$$

Subsequently, Eqs. (13)-(14) were introduced into the eq. (15), and the differential equations of meshing element $j(j=1,2)$ were deduced, which could be expressed as

$$
\mathbf{M}_{m j} \ddot{\mathbf{X}}_{m j}+\left(\mathbf{C}_{m j}+\left[\begin{array}{cc}
\Omega_{p j} \mathbf{G}_{p j} & \\
& \Omega_{g j} \mathbf{G}_{g j}
\end{array}\right]\right) \dot{\mathbf{X}}_{m j}+\mathbf{K}_{m j} \mathbf{X}_{m j}=\mathbf{F}_{j}+\mathbf{F}_{e j}
$$

where $\mathbf{X}_{m j}, \dot{\mathbf{X}}_{m j}$ and $\ddot{\mathbf{X}}_{m j}$ are the displacement, velocity and acceleration vectors of the meshing 
unit $j$, respectively; $\Omega_{p j}$ and $\Omega_{g j}$ indicate the rotation speeds of the main and driven gears of the meshing unit $j$, respectively; $\mathbf{G}_{p j}$ and $\mathbf{G}_{g j}$ are the gyro matrices of the meshing unit $j$, respectively; $\mathbf{F}_{j}$ is the internal excitation force, which could be shown as

$$
F_{j}=\left(k_{h j}(t) e_{n j}(t)+c_{m j} \dot{e}_{n j}(t)\right) \mathbf{B}_{j}^{T}
$$

Here $\mathbf{B}_{j}=\left[n_{p x}, n_{p y}, n_{p z}, \lambda_{p x}, \lambda_{p y}, \lambda_{p z},-n_{p x},-n_{p y},-n_{p z},-\lambda_{p x},-\lambda_{p y},-\lambda_{p z}\right]^{T}$.

$\mathbf{F}_{e j}$ refers to the external excitation force of the engagement unit $j$, which could be given by

$$
\begin{aligned}
& \mathbf{F}_{e j}=\left[\begin{array}{ll}
\mathbf{F}_{e p j} & \mathbf{F}_{e g j}
\end{array}\right]^{T} \\
& \mathbf{F}_{e p j}=\left[m_{p j} e_{p j} \Omega_{p j}^{2} \cos \left(\Omega_{p j} t\right) \quad m_{p j} e_{p j} \Omega_{p j}^{2} \sin \left(\Omega_{p j} t\right) \quad 0 \quad 0000\right]
\end{aligned}
$$

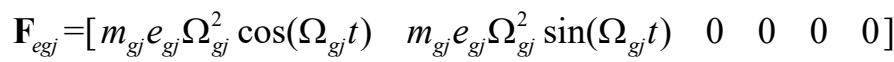

$\mathbf{M}_{m j}$ means the mass matrix of meshing element $j$, which could be written as

$$
\begin{gathered}
\mathbf{M}_{m j}=\left[\begin{array}{ll}
\mathbf{M}_{m p j} & \mathbf{M}_{m g j}
\end{array}\right] \\
\mathbf{M}_{m p j}=\operatorname{diag}\left(m_{p j x}, m_{p j y}, m_{p j z}, I_{p j x}, I_{p j y}, I_{p j z}\right) \\
\mathbf{M}_{m g j}=\operatorname{diag}\left(m_{g j x}, m_{g j y}, m_{g j z}, I_{g j x}, I_{g j y}, I_{g z j}\right)
\end{gathered}
$$

In the global coordinate system, the stiffness matrix $\mathbf{K}_{m j}$ and damping matrix $\mathbf{C}_{m j}$ of meshing element $j$ could be obtained by

$$
\begin{aligned}
\mathbf{K}_{m \mathrm{j}} & =\mathrm{k}_{m} \mathbf{B}_{j}^{T} \mathbf{B}_{j} \\
\mathbf{C}_{m j} & =\mathrm{c}_{m j} \mathbf{B}_{j}^{T} \mathbf{B}_{j}
\end{aligned}
$$

The directions of the stiffness matrix, damping matrix and internal force vector of meshing unit 1 were consistent with the global coordinate system, while that of meshing unit 2 should be converted to the global coordinate system through corresponding coordinate transform, and the expression could be written as

$$
\begin{gathered}
\mathbf{K}_{m 2}=\lambda_{2}^{T}\left(\mathrm{k}_{m} \mathbf{B}_{2}^{T} \mathbf{B}_{2}\right) \lambda_{2} \\
\mathbf{C}_{m 2}=\lambda_{2}^{T}\left(c_{m} \mathbf{B}_{2}^{T} \mathbf{B}_{2}\right) \lambda_{2} \\
\mathbf{F}_{2}=\lambda_{2}^{T} \mathbf{F}_{2}
\end{gathered}
$$

Additionally, the driven gear of the first gear pair and the driving gear of the second gear pair were connected by the oblique tail shaft, whose mass matrix ( $\mathbf{M}_{m g 1}$ and $\mathbf{M}_{m p 2}$ ), gyro matrix ( $\mathbf{G}_{g 1}$ and $\left.\mathbf{G}_{p 2}\right)$, and external excitation vector $\left(\mathbf{F}_{e g 1}\right.$ and $\left.\mathbf{F}_{e p 2}\right)$ should be converted to the global coordinate system by way of the matrix $\lambda_{2}$; meanwhile, the mass matrix $\mathbf{M}_{m g 2}$, gyro matrix $\mathbf{G}_{g_{2}}$ and external excitation vector $\mathbf{F}_{e g 2}$ of the second gear pair should be transformed by matrix $\lambda_{3}$.

\subsection{Modeling of laminated membrane coupling}

Laminated membrane couplings were extensively employed in the helicopter tail transmission system to connect various hollow shaft, as exhibited in Fig. 7, including flange plates, diaphragm groups and other important parts. The laminated membrane coupling was affected by multiple forces such as torque, radial shear force and axial tensile force during the working process. In this study, Ansys software was utilized to perform finite element simulation on the laminated membrane coupling, and the stiffness in all directions was calculated. Moreover, Fig. 8 demonstrated the coupling's finite element mesh model. The material parameters of the coupling were presented in Table 3. 

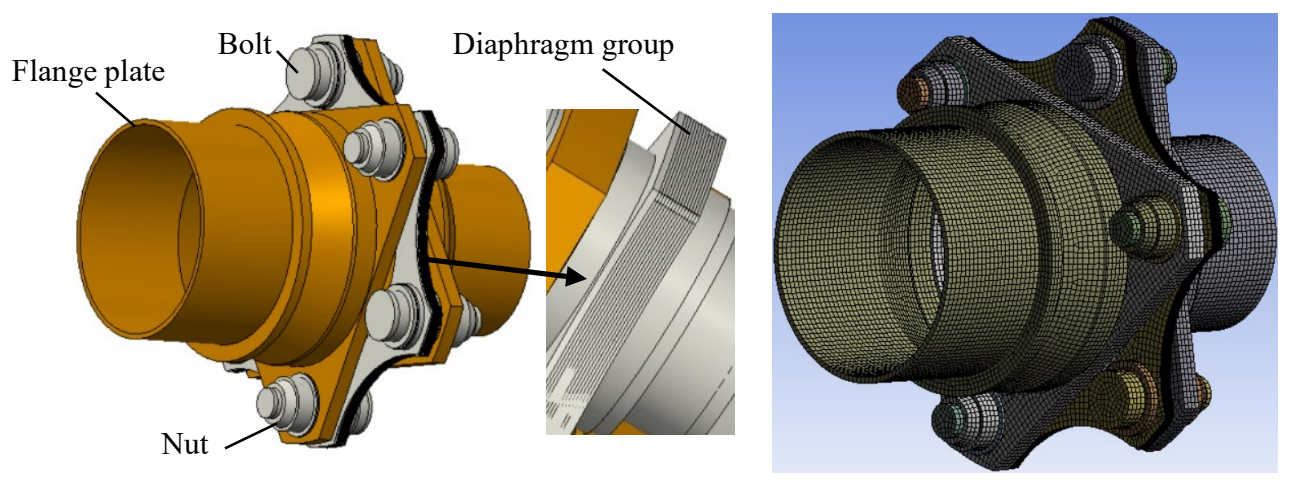

Fig.7 3D model of laminated membrane coupling

Fig.8 Mesh model of laminated membrane coupling

Table 3 Material parameters of laminated membrane coupling

\begin{tabular}{ccccc}
\hline \multirow{2}{*}{ Item } & Material & \multicolumn{3}{c}{ Material Properties } \\
\cline { 3 - 5 } & & Density $\left(\mathrm{kg} / \mathrm{m}^{3}\right)$ & Elastic modulus (MPa) & Poisson's ratio \\
\hline Flange plate & 30CrNi4MoA & 7885 & $2.04 \mathrm{e} 5$ & 0.307 \\
Diaphragm group & $1 \mathrm{Cr} 17 \mathrm{Ni7E} 4$ & 7709 & $2.12 \mathrm{e} 5$ & 0.27 \\
Nut & $30 \mathrm{CrMoA}$ & 7820 & $2.09 \mathrm{e} 5$ & 0.279 \\
Bolt & $30 \mathrm{Ni4CrMoA}$ & 7849 & $2.04 \mathrm{e} 5$ & 0.308 \\
\hline
\end{tabular}

The stiffness matrix $K_{c k}(k=1,2)$ of the diaphragm group could be given as

$$
K_{c k}=\left[\begin{array}{cc}
K_{\text {coupling }} & -K_{\text {coupling }} \\
-K_{\text {coupling }} & K_{\text {coupling }}
\end{array}\right]
$$

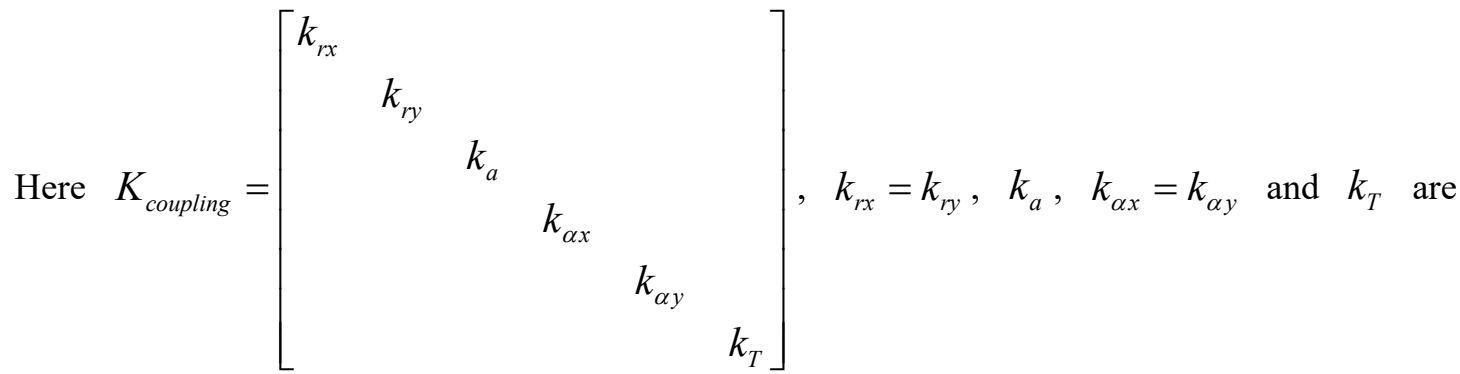

the radial, axial, angular and torsional stiffness of the laminated membrane coupling, respectively, as shown in Table 4.

Table 4 Stiffness of laminated membrane coupling

\begin{tabular}{cc}
\hline Stiffness & Result \\
\hline Radial stiffness $(\mathrm{N} / \mathrm{m})$ & $9.9 \mathrm{e} 8$ \\
Axial stiffness $(\mathrm{N} / \mathrm{m})$ & $8.8 \mathrm{e} 4$ \\
Angular stiffness $(\mathrm{Nm} / \mathrm{rad})$ & $4.2 \mathrm{e} 4$ \\
Torsional stiffness $(\mathrm{Nm} / \mathrm{rad})$ & $6.5 \mathrm{e} 5$ \\
\hline
\end{tabular}

To verify the accuracy of the simulation results, the electro-hydraulic servo torsion test bench was employed to conduct an analogue test on the laminated membrane coupling, and the stiffness of the laminated coupling in the torsional direction was computed, as shown in Fig. 9. The torsion test bench mainly involved acquisition system, loading device and cooling system 
and so on.

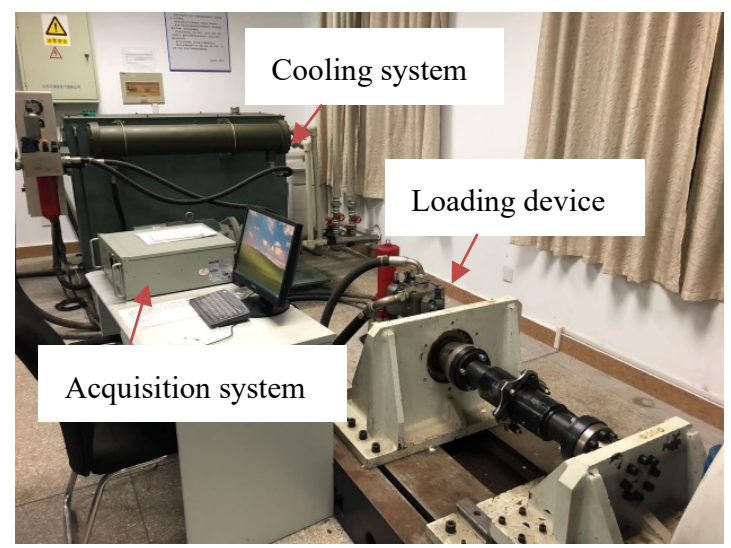

(a) Torsion test rig

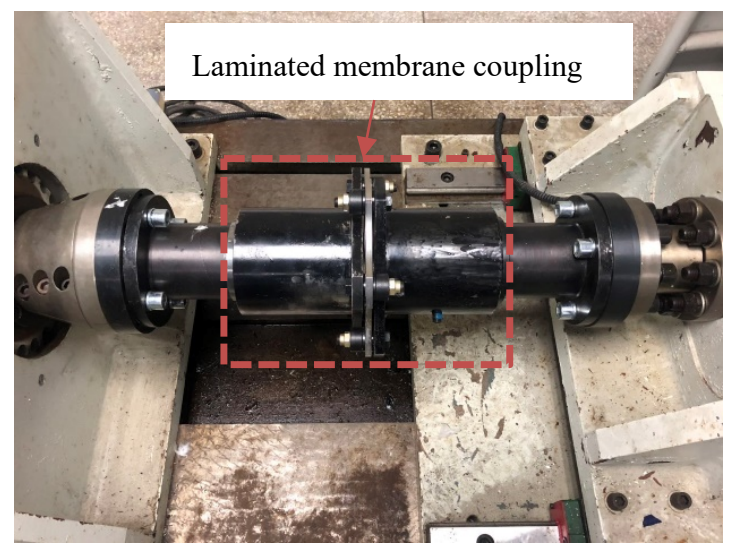

(b) Test piece

Fig. 9 Schematic diagram of torsion test bench

The curves of torque versus rotation angle under forward and reverse rotation were obtained by controlling the angular displacement, as illustrated in Fig. 10. It could be observed that the forward and reverse torsional stiffness of the laminated coupling were identical, and the torsional stiffness's value varied slightly. For the initial stage of loading, the torque did not vary, which was mainly brought about by the existence of circumferential clearance. On this basis, the torsional stiffness of the test piece was obtained by using the same parameter setting as the coupling in the helicopter tail drive in ANSYS simulation, and compared with the test results, as manifested in Table 5. The error between the test and simulation results was $7.3 \%$, which could meet the actual engineering accuracy requirements. Therefore, the stiffness of the laminated membrane coupling obtained by simulation in each direction contained a certain accuracy, which could characterize the dynamic characteristics of the laminated membrane coupling.

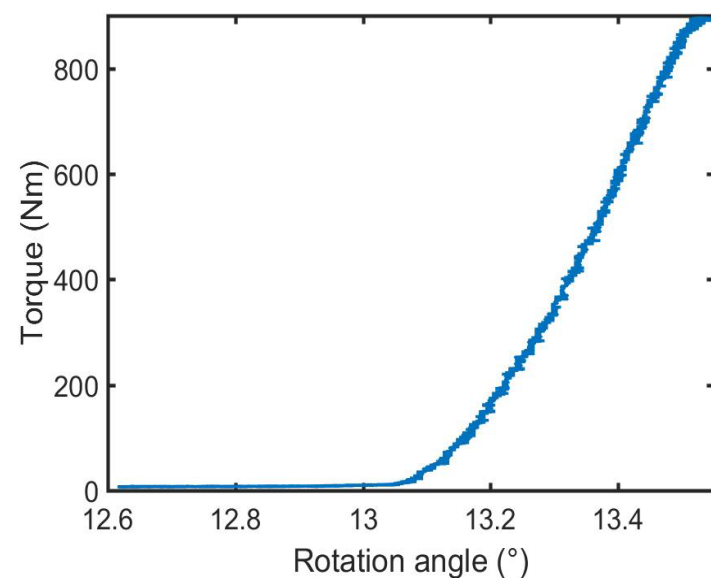

(a) Forward rotation

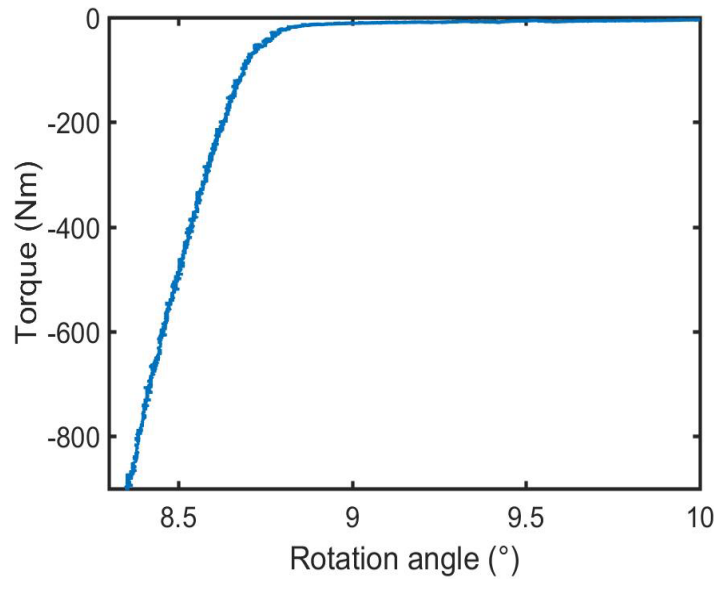

(b) Reverse rotation

Fig. 10 Curve of torque with the rotation angle

Table 5 Comparison of simulation and test data

\begin{tabular}{cccc}
\hline Stiffness & Experiment Result & Simulation Result & Error \\
\hline Torsional stiffness $(\mathrm{Nm} / \mathrm{rad})$ & $1.779 \mathrm{e} 5$ & $1.65 \mathrm{e} 5$ & $7.3 \%$ \\
\hline
\end{tabular}

Furthermore, the laminated membrane coupling was installed on the oblique tail shaft, so the stiffness matrix was converted to the global coordinate system by the coordinate transformation matrix $\lambda_{2}$. 


\subsection{Modeling of ball bearing}

The system was supported by eight angular contact ball bearings. The bearing is equivalent to a spring-damping element in this study; at the same time, due to the scanty coupled action between the degrees of freedom, only the stiffness and damping values of the main term are retained. Hence, the stiffness matrix $\boldsymbol{K}_{b l}$ and damping matrix $\boldsymbol{C}_{b l}(l=1,2,3,4,5,6,7,8)$ of the bearing could be acquired by

$$
\begin{gathered}
\boldsymbol{K}_{b l}=\operatorname{diag}\left(k_{x x}, k_{y y}, k_{z z}, k_{\theta x}, k_{\theta y}, 0\right) \\
\boldsymbol{C}_{b l}=\operatorname{diag}\left(c_{x x}, c_{y y}, c_{z z}, c_{\theta x}, c_{\theta y}, 0\right)
\end{gathered}
$$

Also, to characterize the bearing's stiffness and damping matrix in the global coordinate system, corresponding coordinate transformations were required. $\lambda_{1}, \lambda_{2}$ and $\lambda_{3}$ represent the coordinate transformation matrix of bearings 1-2, 3-6 and 7-8, respectively.

\subsection{The coupled dynamic equations of the whole system}

On this basis, dynamic equations of the coupled system were established [32-33], which could be written as

$$
\mathbf{M} \ddot{\mathbf{X}}(t)+(\mathbf{C}-\Omega \mathbf{G}) \dot{\mathbf{X}}(t)+\mathbf{K X}(t)=\mathbf{Q}
$$

where $\mathbf{M}, \mathbf{C}, \mathbf{G}$ and $\mathbf{K}$ denote the mass, damping, gyro and stiffness matrix of the system in the global coordinate system, respectively; $\mathbf{X}, \dot{\mathbf{X}}, \ddot{\mathbf{X}}$ and $\mathbf{Q}$ represent the displacement, velocity, acceleration and force vector of the system in the global coordinate system, respectively.

\section{Solution and discussion}

The system possessed many degrees of freedom, and it was difficult to get accurate results utilizing the theoretical solution method. Therefore, the Newmark numerical algorithm was employed to solve the dynamic equations, where the integral step size was $1 / 400$ of the excitation frequency. Moreover, the material of the shaft in the helicopter is aluminium alloy, whose elastic model $E$, Poisson's ratio $\mu$ and density $\rho$ are $6.8 \mathrm{e} 4 \mathrm{MPa}, 0.3$ and $2800 \mathrm{~kg} / \mathrm{m}^{3}$, respectively. The relevant parameters of the beam element and bearing are displayed in Table 6 and Table 7, respectively.

Table 6 Shaft element parameters.

\begin{tabular}{cccccccc}
\hline Node to node & $1-2$ & $2-3$ & $3-4$ & $4-5$ & $6-7$ & $7-8$ & $8-9$ \\
\hline Outer diameter (m) & 0.09 & 0.09 & 0.09 & 0.09 & 0.09 & 0.09 & 0.09 \\
Inner diameter (m) & 0.084 & 0.084 & 0.084 & 0.084 & 0.084 & 0.084 & 0.084 \\
$\quad$ Length (m) & 0.05 & 0.05 & 0.05 & 0.05 & 0.08 & 0.08 & 0.08 \\
\hline Node to node & $10-11$ & $11-12$ & $12-13$ & $14-15$ & $15-16$ & $17-18$ & $18-19$ \\
\hline Outer diameter (m) & 0.09 & 0.09 & 0.09 & 0.09 & 0.09 & 0.09 & 0.09 \\
\hline
\end{tabular}




\begin{tabular}{cccccccc}
\hline Inner diameter (m) & 0.084 & 0.084 & 0.084 & 0.084 & 0.084 & 0.084 & 0.084 \\
Length (m) & 0.2 & 0.2 & 0.2 & 0.2 & 0.2 & 0.08 & 0.08 \\
\hline Node to node & $19-20$ & $21-22$ & $22-23$ & $23-24$ & $24-25$ & $25-26$ & $26-27$ \\
\hline Outer diameter (m) & 0.09 & 0.09 & 0.09 & 0.09 & 0.09 & 0.086 & 0.086 \\
Inner diameter (m) & 0.084 & 0.084 & 0.084 & 0.084 & 0.084 & 0.08 & 0.08 \\
Length (m) & 0.08 & 0.05 & 0.05 & 0.05 & 0.05 & 0.1 & 0.1 \\
\hline
\end{tabular}

Table 7 Bearing parameters.

\begin{tabular}{ccc}
\hline Stiffness & Bearing $1-4$ & Bearing 5-8 \\
\hline $\mathrm{k}_{x x}, \mathrm{k}_{y y}(\mathrm{~N} / \mathrm{m})$ & $2 \mathrm{e} 8$ & $2 \mathrm{e} 8$ \\
$\mathrm{k}_{z z}(\mathrm{~N} / \mathrm{m})$ & $1 \mathrm{e} 8$ & $1 \mathrm{e} 8$ \\
$\mathrm{k}_{\theta x}, \mathrm{k}_{\theta y}(\mathrm{Nm} / \mathrm{rad})$ & $1 \mathrm{e} 6$ & $1 \mathrm{e} 8$ \\
\hline Damping & Bearing $1-4$ & Bearing 5-8 \\
\hline $\mathrm{c}_{x x}, \mathrm{c}_{y y}(\mathrm{Ns} / \mathrm{m})$ & $1 \mathrm{e} 3$ & $1 \mathrm{e} 3$ \\
$\mathrm{c}_{z z}(\mathrm{Ns} / \mathrm{m})$ & $1 \mathrm{e} 3$ & $1 \mathrm{e} 3$ \\
$\mathrm{c}_{\theta x}, \mathrm{c}_{\theta y}(\mathrm{Ns} / \mathrm{rad})$ & 800 & 800 \\
\hline
\end{tabular}

\subsection{Influence of laminated membrane coupling on dynamic properties of systems}

In the helicopter tail transmission system, a laminated membrane coupling was contained between the oblique tail shaft and gear shaft to compensate the installation error between them. In previous studies, most of the gear dynamic models did not consider the flexibility of laminated membrane coupling. Therefore, the effect of laminated membrane coupling on the system's dynamic behaviour was discussed without the eccentricity here.

The coupled system was mainly subjected to the internal excitation produced by two gear-pairs. Fig. 11(a) demonstrated the transverse vibration's amplitude-frequency response curve of the oblique tail shaft at node 13 in the speed range of $0-8000 \mathrm{r} / \mathrm{min}$ with and without laminated membrane coupling. Two amplitudes in the figure were corresponding to the case that the meshing frequency of the first and second gear-pair was equal to the system's natural frequency, respectively. It was obvious that gear pair exerted a critical effect on the vibration response of the oblique tail shaft when the coupling stiffness was taken into account. The amplitude of the oblique tail shaft at the critical point was significantly reduced, which was conducive to cross the resonance point. However, the influence of the coupling stiffness on the natural frequency of the system was light. Besides, the vibration behaviours of the system were less fluctuant on the position that was not isolated by laminated membrane coupling. Fig. 11(b) illustrated the amplitude-frequency response curve of the lateral vibration response of node 6 in gear 2. The meshing force of the first gear-pair exerted little effect on the vibration response of node 6 with and without the laminated membrane coupling, while that of the second gear-pair significantly influenced the vibration response of node 6 due to the vibration isolation effect of the laminated membrane coupling in the vibration transmission. 


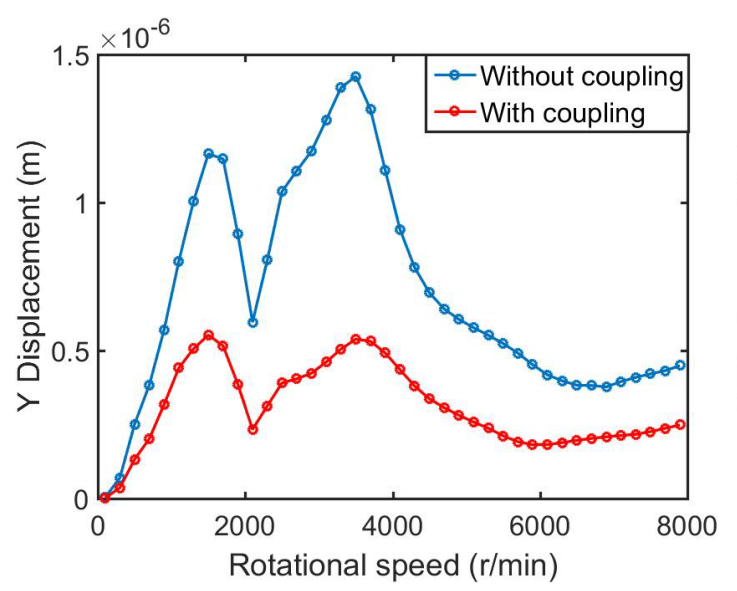

(a) node 13

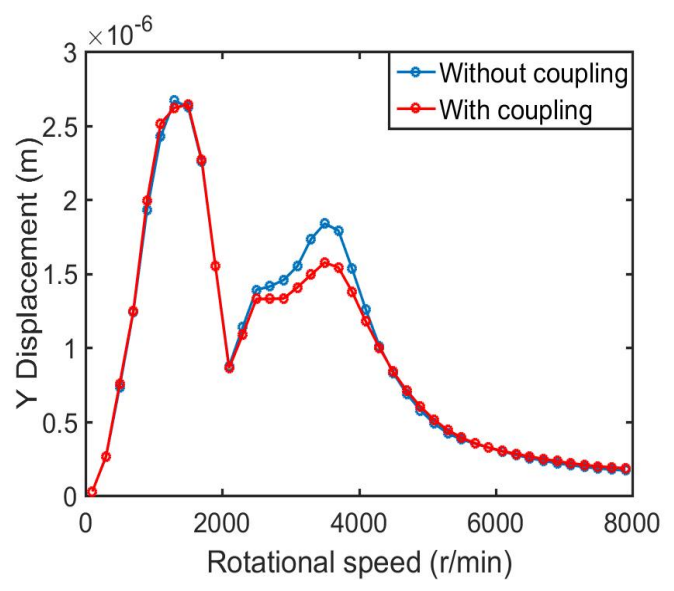

(b) node 6

Fig. 11 Amplitude-frequency response curve of lateral vibration response of the system

Taking node 6 in gear 2 and node 20 in gear 3 as examples, a detailed analysis was carried out to study the effect of laminated membrane coupling on the coupled action between gear pairs. Spectrograms of vibration displacement of nodes 6 and 20 were calculated at the speed of $4000 \mathrm{r} / \mathrm{min}$, respectively, as shown in Fig. 12. It could be known that due to the mutual influence of two gear pairs during the movement, the meshing frequency of the first and the second gear pairs, i.e. $f_{m 1}$ and $f_{m 2}$, appeared simultaneously in nodes 6 and 20. The meshing frequencies of nodes 6 and 20 were reduced when the coupling stiffness was considered. The related multi-span shafting dynamics research also showed that the laminated membrane coupling held damping effect; similarly, in the geared rotor transmission system, the laminated membrane coupling could not only effectively isolated the vibration but also reduced the coupled effect between gear pairs.

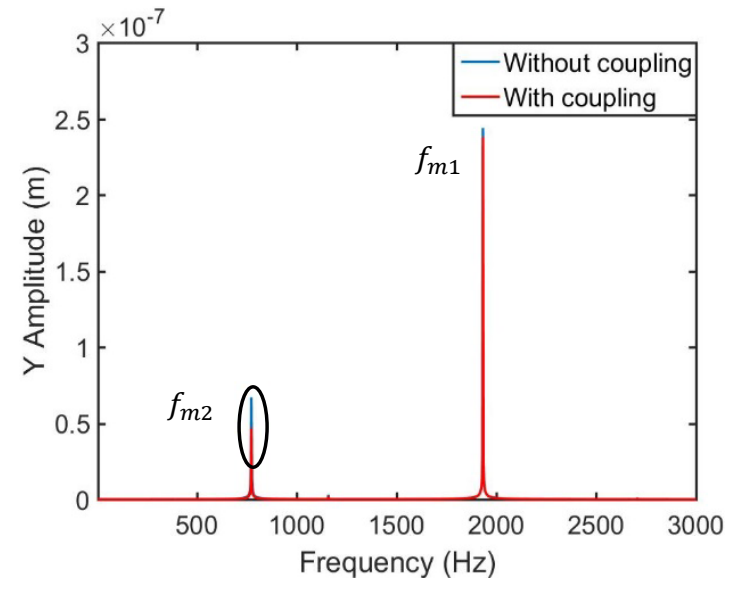

(a) node 6

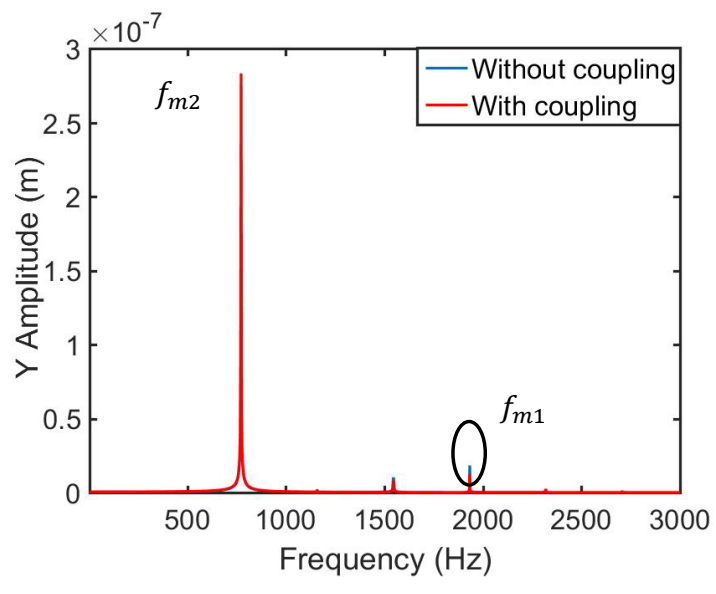

(a) node 20

Fig. 12 Spectrograms of lateral vibration response of the system

\subsection{Influence of gear eccentricity on dynamic properties of systems}

\subsubsection{The effect of the gear eccentricity on the vibration of the oblique tail shaft}

Gear pairs 1 and 2 commonly contained a certain amount of eccentricity due to machining error. In the light, it was assumed that the eccentricity of each gear was $\rho_{1}=5 e-6 \mathrm{~m}, \rho_{2}=5 e-6 \mathrm{~m}$, $\rho_{3}=5 e-6 \mathrm{~m}$ and $\rho_{4}=5 \mathrm{e}-6 \mathrm{~m}$, respectively. In order to study the influence of the gear eccentricity on the of the oblique tail shaft's vibration response, the waterfall diagram of transverse and torsional vibration of node 13 in the oblique tail shaft was solved under the speed range of 0 - 
$8000 \mathrm{r} / \mathrm{min}$, as presented in Fig. 13. It could be observed that the rotation frequency $f_{1}$ of the input shaft, rotation frequency $f_{2}$ of the oblique tail shaft, rotation frequency $f_{3}$ of the output shaft, meshing frequencies, i.e. $f_{m 1}$ and $f_{m 2}$, appeared simultaneously in the torsional vibration, and the rotation frequency components of each shaft rise continuously with the increase of rotational speed. The main reason was that the oblique tail shaft was not only subjected to the meshing force of two gear pairs simultaneously but also there existed a bending-torsion coupled effect at the meshing point. Therefore, the lateral vibration caused by the gear eccentricity exerted an impact on the oblique tail shaft's torsional vibration. However, no other rotational frequency of the shaft was found in the transverse vibration of the oblique tail shaft, in which only the rotation frequency $f_{2}$ and the meshing frequency of two gear pairs, i.e. $f_{m 1}$ and $f_{m 2}$ were appeared. The main reason was that gears 2 and 3 were connected by the oblique tail shaft, so the eccentricity exerted a direct impact on the transverse vibration of the oblique tail shaft; however, the effect of the eccentricity of gears 1 and 4 on the oblique tail shaft's transverse vibration was light through the meshing action of spiral bevel gears. It could be summarized that gear eccentricity had a greater effect on the torsional vibration of the oblique tail shaft compared with the transverse vibration. This result was similar to the result of the parallel shaft gear transmission system in some works of literature [34-35], and the impact of the gear eccentricity on the torsional vibration of the transmission system was greater than that of the transverse vibration.

In the light of the above, the torsional vibration of node 13 in the oblique tail shaft with and without gear eccentricity was calculated at the speed of $6000 \mathrm{r} / \mathrm{min}$, as shown in Fig. 14. It was exhibited that the torsional vibration amplitude of the oblique tail shaft tended to rise due to the effect the gear eccentricity, and the waveform also became more complex; meanwhile, the rotation frequency of each shaft appeared in the frequency spectrum.

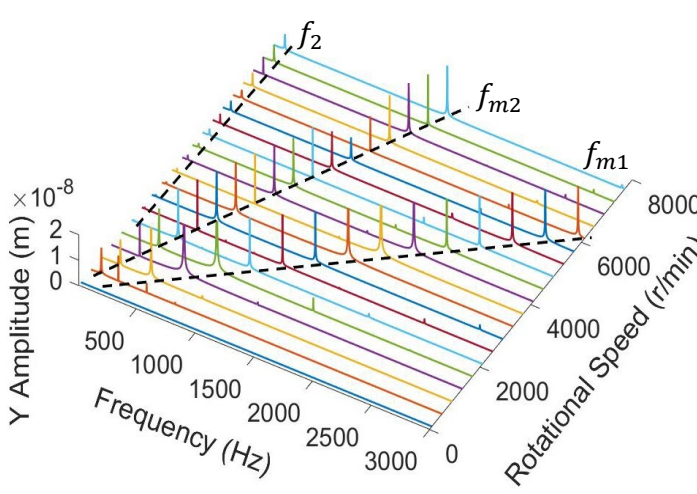

(a) Lateral vibration of node 13

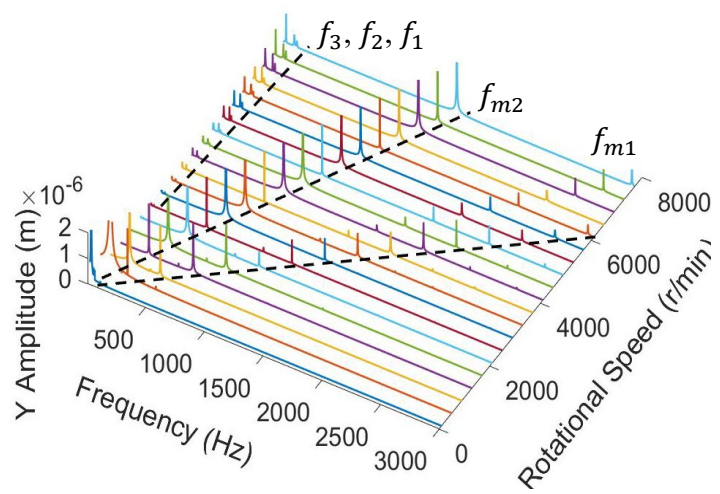

(b) Torsional vibration of node 13

Fig. 13 The waterfall diagram of vibration response of oblique tail shaft with gear eccentricity 


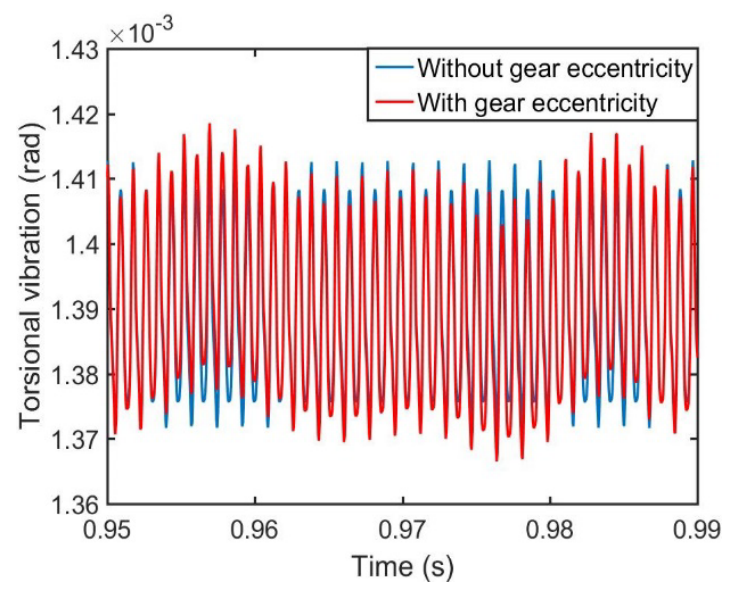

(a) Time history of torsional vibration of node 13

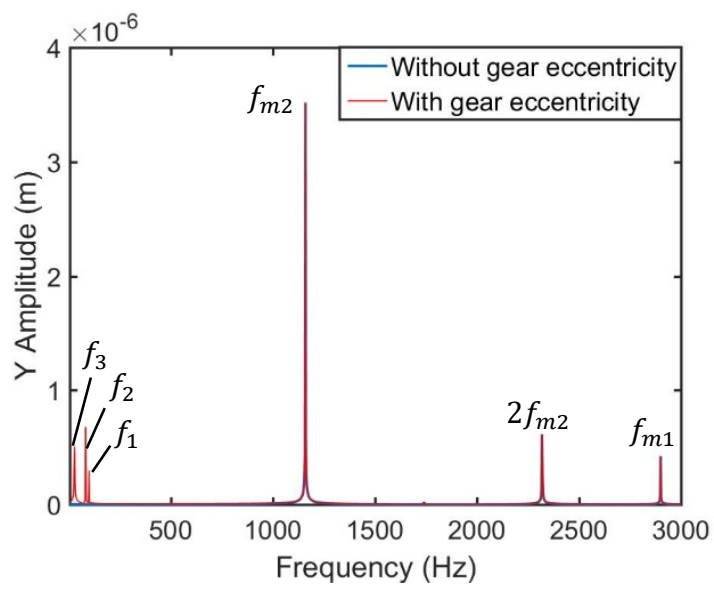

(b) Spectrum of torsional vibration of node 13

Fig.14 Analysis of torsional vibration response of node 13

\subsubsection{Interaction between gear eccentricities}

The waterfall diagrams of the system's lateral and torsional vibration were calculated during the speed range of $0-8000 \mathrm{r} / \mathrm{min}$, and the node 5 at gear 1 and node 20 at gear 3 were chosen to discuss in detail, as displayed in Fig. 15. It was found that there also existed a coupled effect between the first and second gear-pair. Specifically, the transverse vibration of node 5 consisted of the rotation frequency $f_{1}$, meshing frequencies $f_{m 1}$ and $f_{m 2}$ in the first gear-pair; however, the rotation frequency of each shaft, i.e. $f_{1}, f_{2}$ and $f_{3}$, meshing frequencies $f_{m 1}$ and $f_{m 2}$ occurred in the torsional vibration at the same time. Furthermore, the vibration law of node 20 in the second gearpair was similar. It could be a conclusion that compared with the lateral vibration, the coupled effect between the eccentricity mainly affected the torsional vibration in different gear pairs.

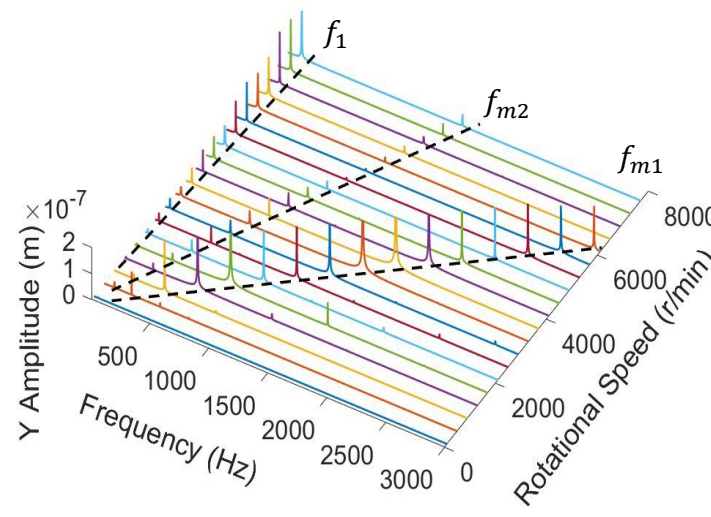

(a) Lateral vibration of node 5

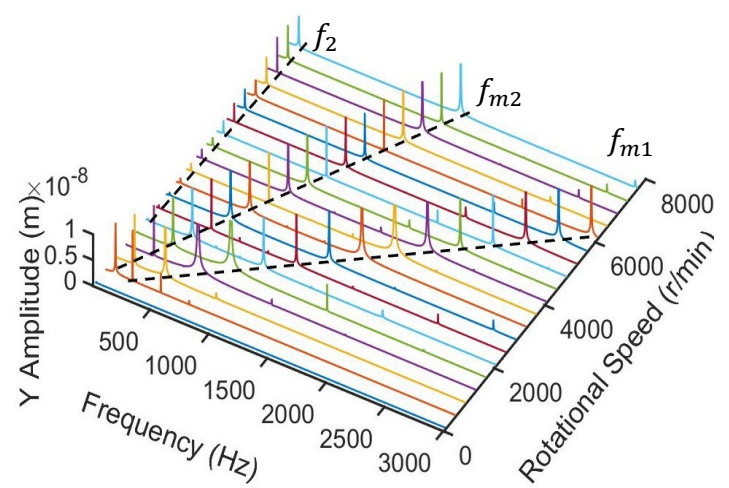

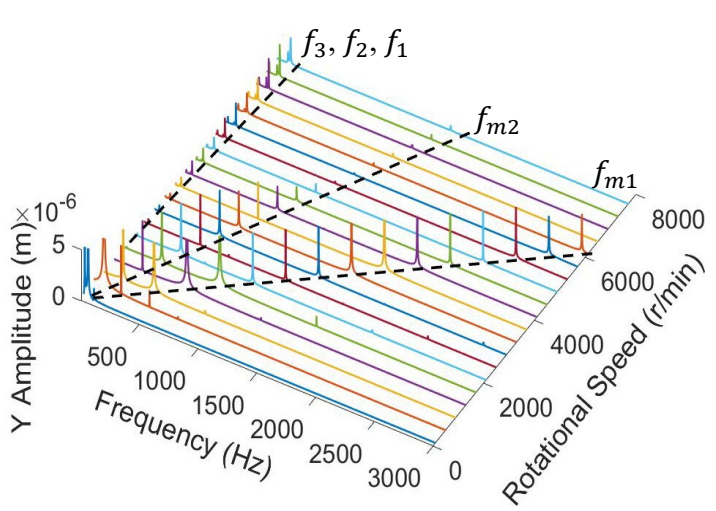

(b) Torsional vibration of node 5

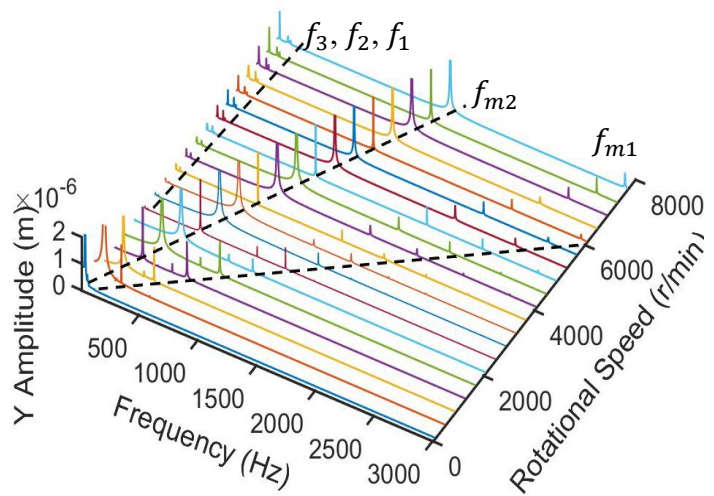



(c) Lateral vibration of node 20
(d) Torsional vibration of node 20

Fig. 15 Waterfall diagram of gear vibration response with gear eccentricity

\subsection{Influence of tail rotor excitation on dynamic properties of systems}

The torsional excitation formed in the tangential direction was taken into consideration in the study. The blade was subject to periodic tangential torque when the tail rotor was running in the uneven flow field, which was the main source of torsional excitation of the helicopter tail transmission system, and the excitation frequency was the blade frequency or blade doubling frequency. In the actual calculation process, the blade frequency excitation was usually expressed as the form of the Fourier series of the frequency expansion, which could be written as

$$
T_{t}=T_{s}+\sum_{i=1}^{n} T_{i z_{p}} \sin \left(i z_{p} \omega_{t} t+\varphi_{i z_{p}}\right)
$$

Here $\omega_{t}$ represents the speed of the tail rotor; $z_{p}$ is the number of blades of the tail rotor; $T_{s}$ represents the stable value of the tail rotor excitation; $T_{i z_{p}}$ denotes the amplitude of the ith excitation moment, i.e. $T_{i z_{p}}=\alpha T_{s}$, in which $\alpha=0.03 \sim 0.1 ; \varphi_{i z_{p}}$ refers to the phase angle of the ith excitation moment.

The second-order component of the Fourier series was utilized in this study, which could be expressed as follows

$$
T_{t}=T_{s}+T_{z_{p}} \sin \left(z_{p} \omega_{t} t+\varphi_{1 z_{p}}\right)+T_{2 z_{p}} \sin \left(2 z_{p} \omega_{t} t+\varphi_{2 z_{p}}\right)
$$

where $z_{p}=4, \alpha=0.05, \varphi_{1 z_{p}}=0$ and $\varphi_{2 z_{p}}=0$.

Firstly, the waterfall diagram of the transverse and torsional vibration of node 13 in the oblique tail shaft in the speed range of $0-8000 \mathrm{r} / \mathrm{min}$ was calculated so as to investigate the effect of the tail rotor excitation on the coupled system's vibration response, as shown in Fig. 16. It was revealed that the excitation frequency $f_{p}$ of the tail rotor occurred in the transverse vibration and torsional vibration simultaneously. For a clearer demonstration, the frequency spectrum of transverse and torsional vibration of node 13 at the speed of $6000 \mathrm{r} / \mathrm{min}$ was calculated, as observed in Fig. 17. Rotation frequency $f_{2}$, tail rotor excitation frequency $f_{p}$, meshing frequency, i.e. $f_{m 1}$ and $f_{m 2}$, were displayed in the lateral vibration. The main reason was the bending-torsional coupled effect at the mesh point of gear-pair and then the transverse vibration of the tail shaft was affected by the torsional excitation of the tail rotor. The shaft frequency, i.e. $f_{3}, f_{2}$ and $f_{1}$, tail rotor excitation frequency $f_{p}$, meshing frequency, i.e. $f_{m 2}, f_{m 1}$, were showed in the torsional vibration at the same time; meanwhile, the excitation frequency component of the tail rotor in torsional vibration was higher, so the influence was more prominent.
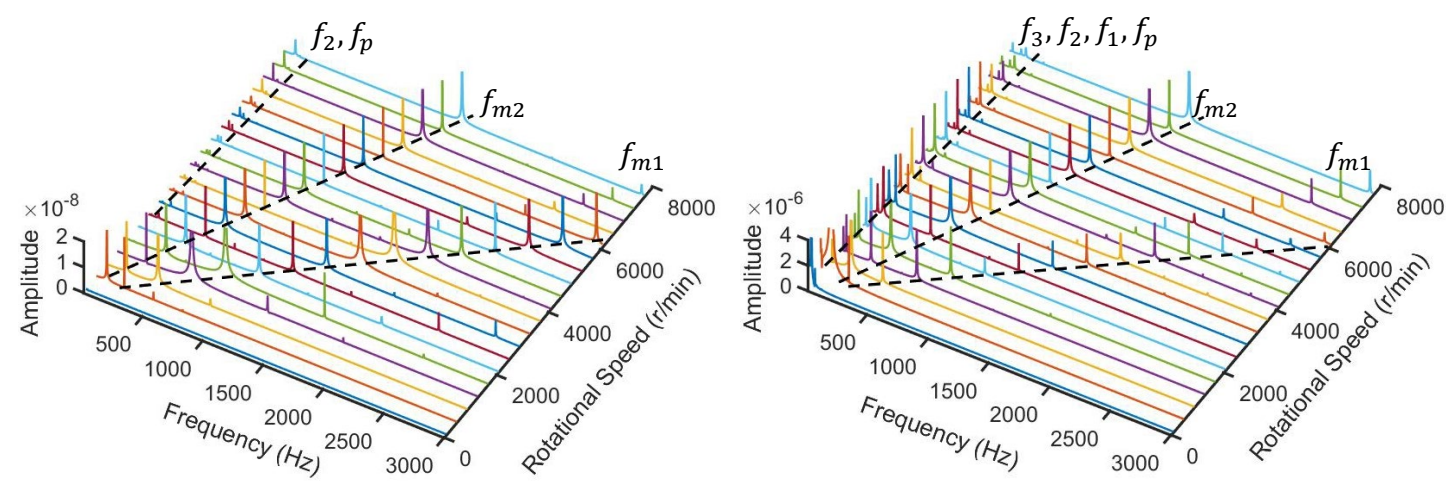
(a) Lateral vibration of node 13

(b) Torsional vibration of node 13

Fig. 16 Waterfall diagram of vibration response of node 13 in the oblique tail shaft with tail rotor excitation

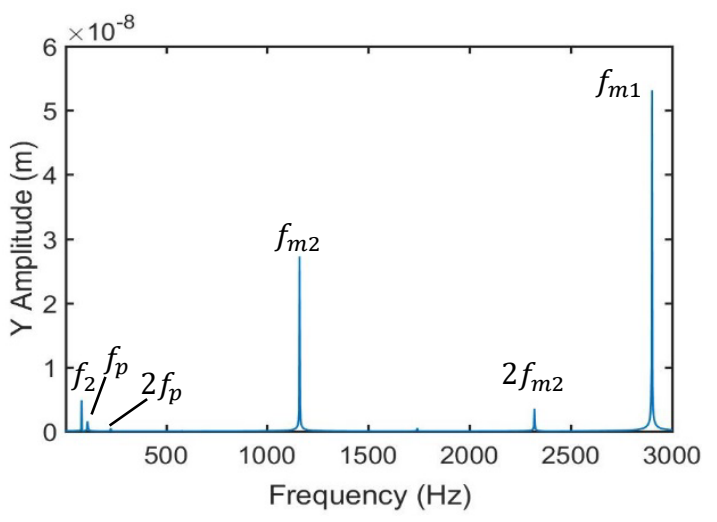

(a) Lateral vibration of node 13

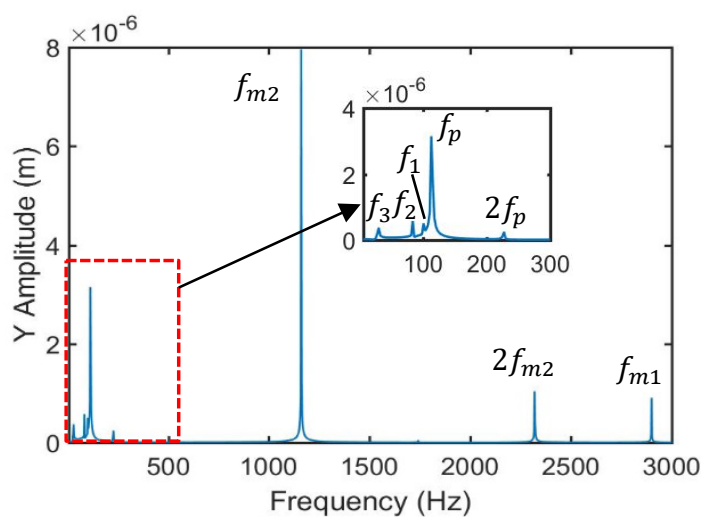

(b) Torsional vibration of node 13

Fig. 17 Spectrogram of vibration response of node 13 in the oblique tail shaft with tail rotor excitation

Furthermore, the vibration responses of node 3 in the input shaft and node 23 in the output shaft were computed, as demonstrated in Figs. 18 and 19, respectively. It can be found that the tail rotor excitation frequency $f_{p}$ did not appear in the spectrogram of transverse vibration at node 3 , while obvious tail rotor excitation frequency was observed in the torsional vibration's spectrogram. Therefore, the effect of the tail rotor excitation on the transverse vibration at node 3 was not prominent; however, the torsional vibration was remarkable. For node 23 , the excitation frequency $f_{p}$ of the tail rotor was obvious in both lateral and torsional vibrations, in which that of the tail rotor in torsional vibration was relatively prominent. So, the tail rotor excitation exerted an effect on both lateral and torsional vibrations, and the torsional vibration was affected considerably. To sum up, the tail rotor excitation exerted an impact on the torsional and lateral vibration of the system, in which the torsional vibration had a greater impact; and the effect gradually decreased from the output shaft to the input shaft, that is, the closer to the tail rotor, the greater the influence.

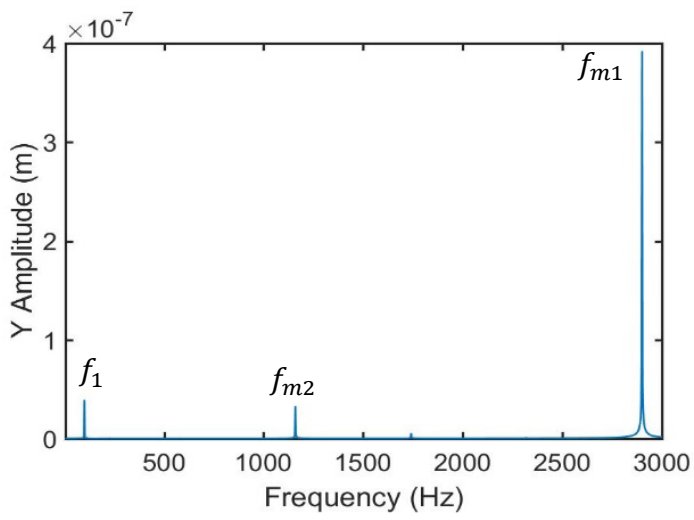

(a) Lateral vibration

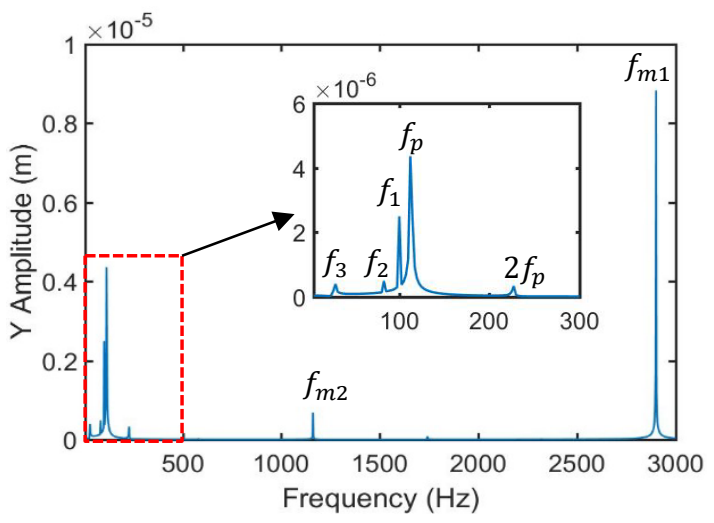

(b) Torsional vibration

Fig. 18 Spectral diagram of vibration response of node 3 in the input shaft with tail rotor excitation 


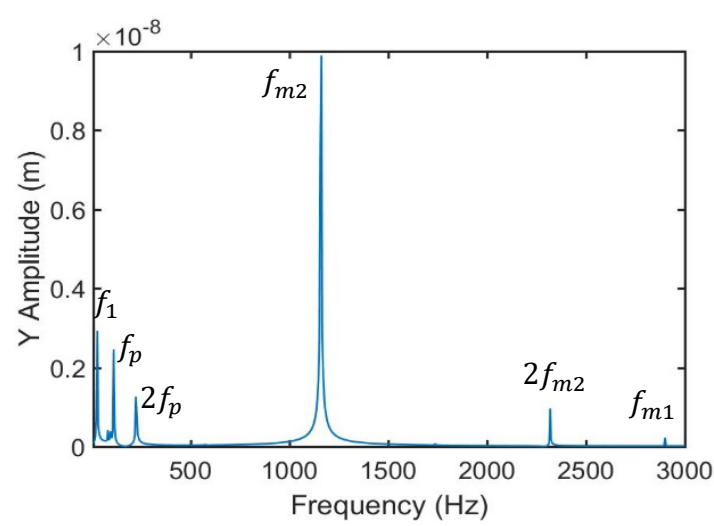

(a) Lateral vibration

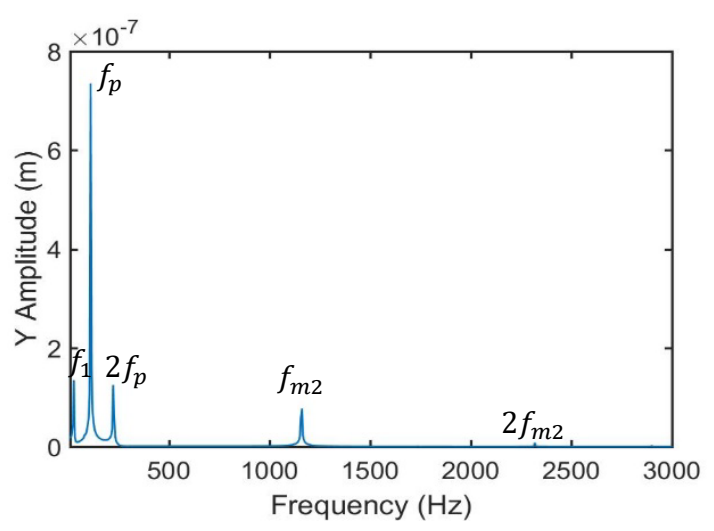

(b) Torsional vibration

Fig. 19 Spectral diagram of vibration response of node 23 in output shaft with tail rotor excitation

\subsection{Influence of length of the oblique tail shaft on dynamic characteristics of systems}

The coupled system composed of the intermediate and tail gearbox was connected by a long thinwalled oblique tail shaft in the tail transmission system, whose vibration characteristics were complicated. In the light, the shaft length was taken as $L=0.8 \mathrm{~m}, 1.2 \mathrm{~m}$ and $1.6 \mathrm{~m}$, respectively, so as to study the influence of the length of the oblique tail shaft on the vibration response of the system.

As shown in Fig. 20, the axis trajectories of node 4 at the input shaft, node 13 at the oblique tail shaft and node 23 at the output shaft were obtained, respectively. It could be seen that the axis trajectories of the input and output shaft failed to fluctuate with changing of the length of the oblique tail shaft, but the shaft length exerted a vital effect on the oblique tail shaft itself. The main reason was that with the increase of the shaft length, the bending stiffness decreased correspondingly, so the transverse vibration rose obviously, which would lead to the rub-impact fault easily in the process of rotation.

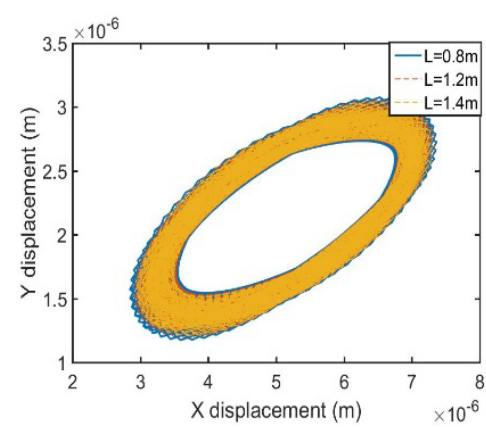

(a) node 4

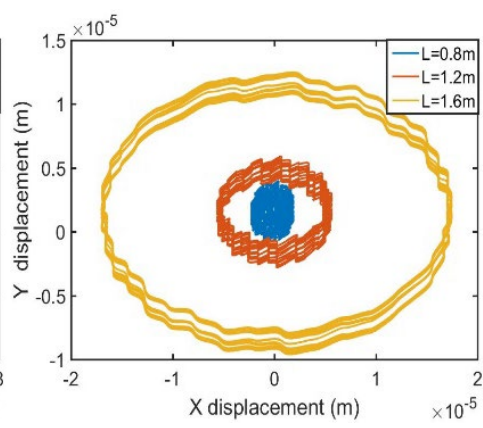

(b) node 13

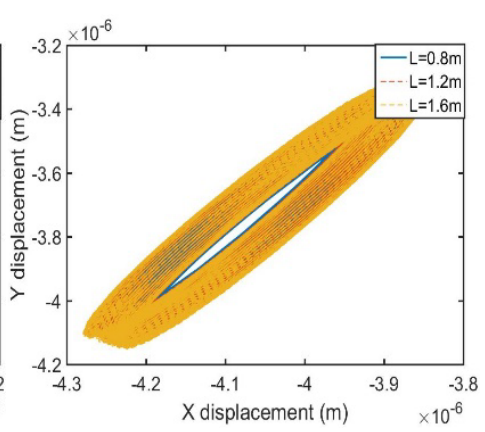

(c) node 23

Fig. 20 Axis locus

Then, time-domain diagrams of the torsional vibration corresponding to the different length of the oblique tail shaft were solved under the speed of $6000 \mathrm{r} / \mathrm{min}$, as depicted in Fig. 21. It could be seen from Figs. 21(a) to (c), with the shaft length rose, the torsional stiffness decreased, which resulted in the location of the torsional vibration centre also increasing. The centre of torsional vibration with various shaft lengths was set to zero position so as to observe the variation of torsional vibration. Meanwhile, the torsional vibration displacement of the tail skew shaft also tended to smaller when the torsional stiffness of the oblique tail shaft became tinier, as shown in Fig. 21(d). Besides, for the torsional vibration of the node 4 and node 23 that were located in the input and output shaft, respectively, the fluctuation of the torsional vibration displacement caused by the 
length variation of the oblique tail shaft was slight, as revealed in Fig. 22. The main reason was that the oblique tail shaft was subjected to the meshing action of two spiral bevel gear-pairs simultaneously, which led to the apparent variation of torsional vibration displacement of the oblique tail shaft. A similar conclusion had been obtained in reference [36], but in which the dynamic modelling of the torsional vibration of the helicopter tail transmission system was only carried out, and few factors were merely considered in the model.

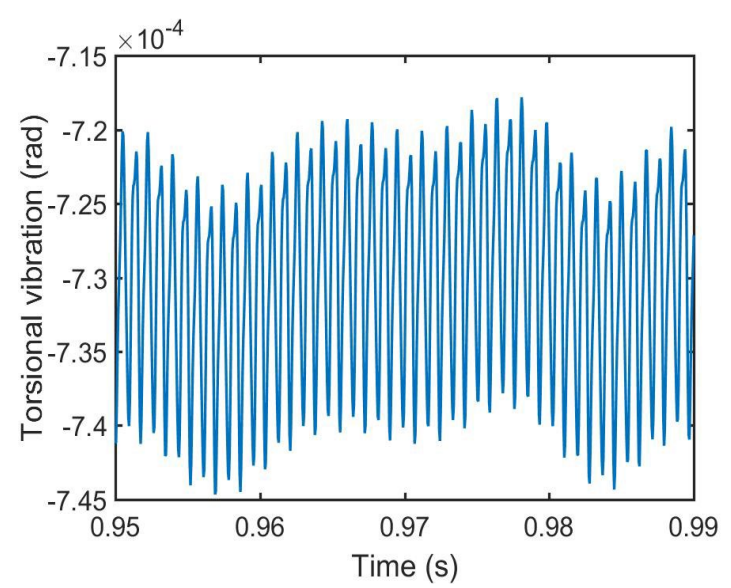

(a) $\mathrm{L}=0.8 \mathrm{~m}$

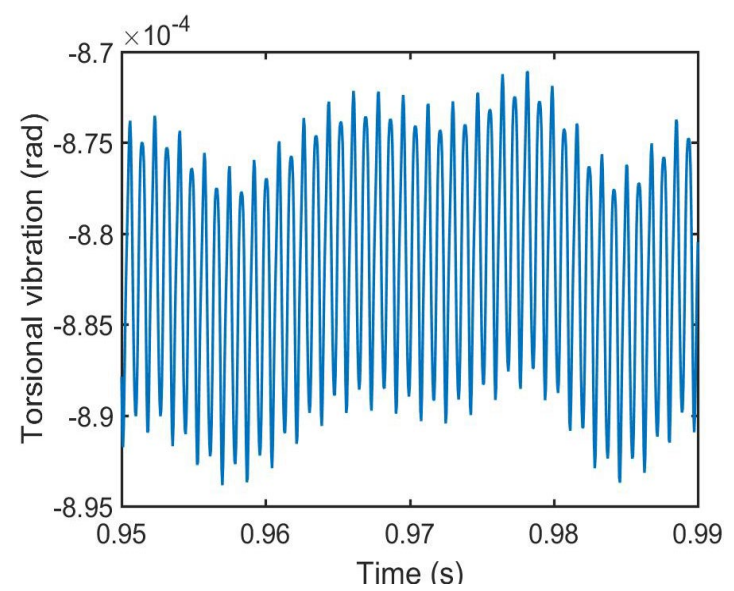

(c) $\mathrm{L}=1.6 \mathrm{~m}$

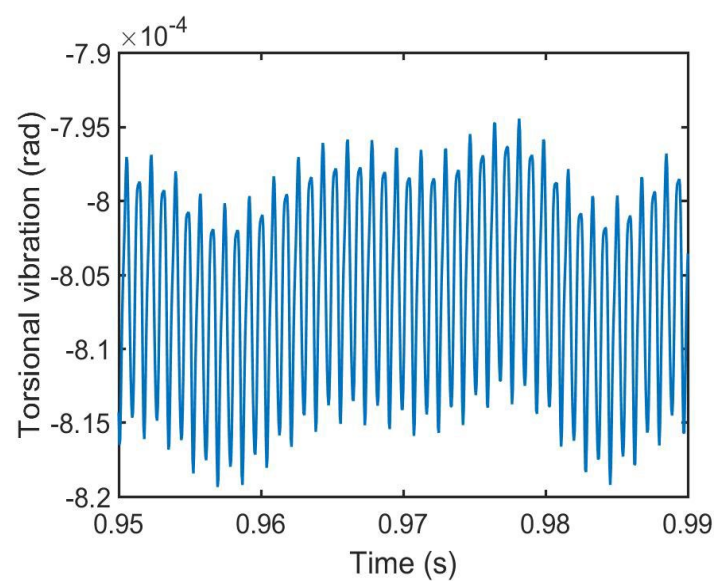

(b) $\mathrm{L}=1.2 \mathrm{~m}$

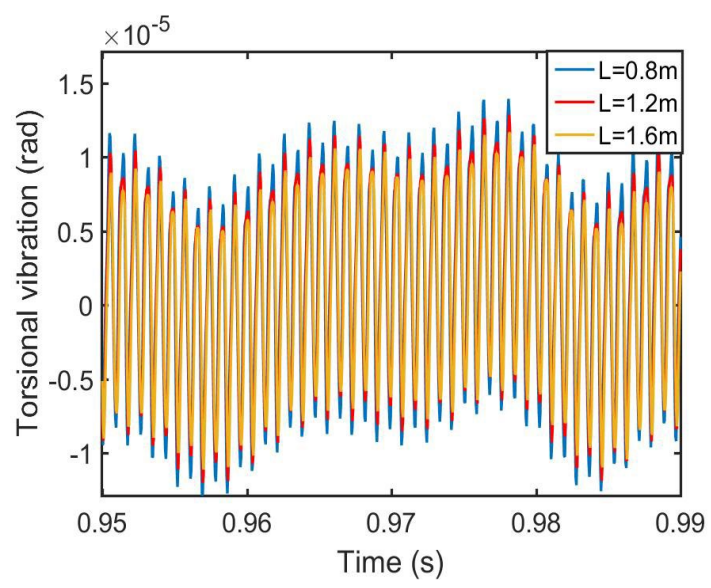

(d) $\mathrm{L}=0.8 \mathrm{~m}, 1.2 \mathrm{~m}, 1.6 \mathrm{~m}$

Fig. 21 Torsional vibration response of oblique tail shaft with various shaft lengths

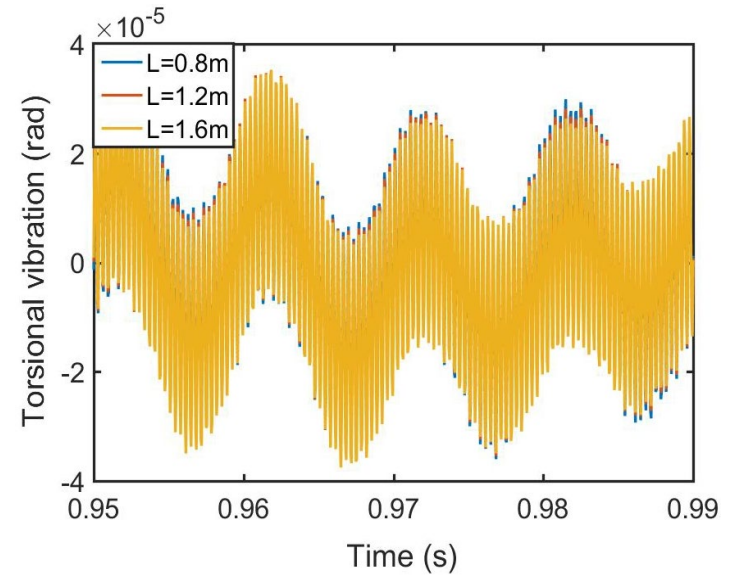

(a) node 4

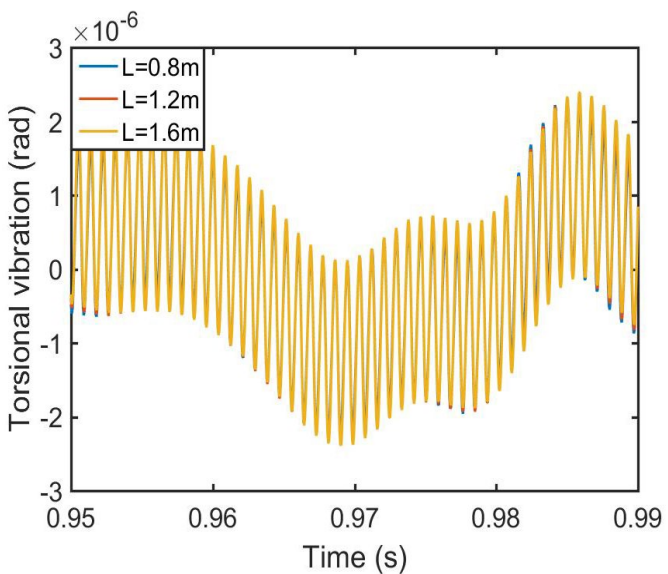

(b) node 23 
Fig. 22 Torsional vibration responses of input and output shaft under various lengths of the oblique tail shaft

\subsection{Influence of transmission error amplitude on dynamic characteristics of systems}

Transmission errors were inevitable due to the geometric structure of the gear or factors such as manufacturing and installation, which held a prominent impact on the dynamics of the coupled system. To investigate the impact of transmission error excitation on the dynamic characteristics of the whole coupled system, the coupled system's vibration responses were calculated when the transmission error excitation amplitude of the gear-pair 1 was set to $1 \mathrm{e}-5 \mathrm{~m}, 1.5 \mathrm{e}-5 \mathrm{~m}$ and $2 e-5 m$, respectively. As manifested in Fig. 23, the time history diagram of node 4 in gear 1 with various transmission errors was exhibited under the speed of $6000 \mathrm{r} / \mathrm{min}$. It could be seen that as the amplitude of the error excitation increases, the vibration response at the gear 1 increases significantly, and the effects on both lateral and torsional vibration were significant. Besides, the vibration response of the oblique tail shaft in node 13 was shown in Fig. 24. Due to the flexuraltorsional coupled vibration effect of the entire system, the effect on the vibration characteristics of the oblique tail shaft also exhibited the corresponding trend, that is, as the gear transmission error excitation rises, the vibration response in all directions was grown, but the variation degree was less than the excitation source. Hence, for multiple pairs of the geared rotor transmission system, the transmission precision of gears should be ensured during parts processing and installation. Once the error limit was exceeded, the vibration of the entire coupled system would be deteriorated, thereby reducing the service life.

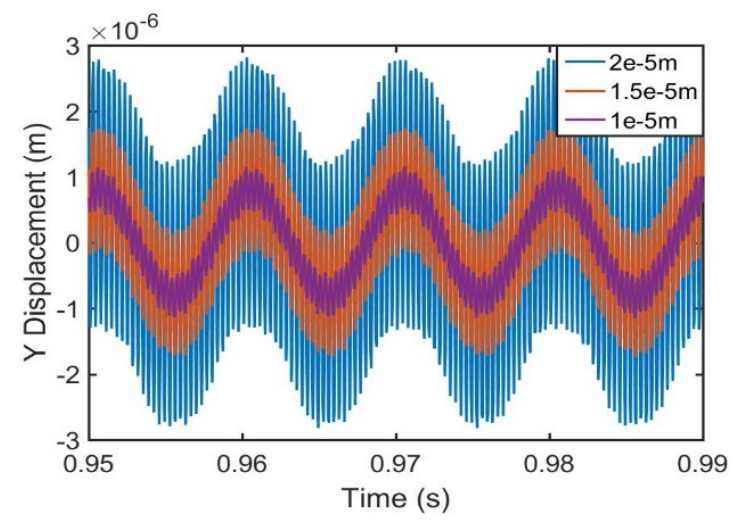

(a) Lateral vibration

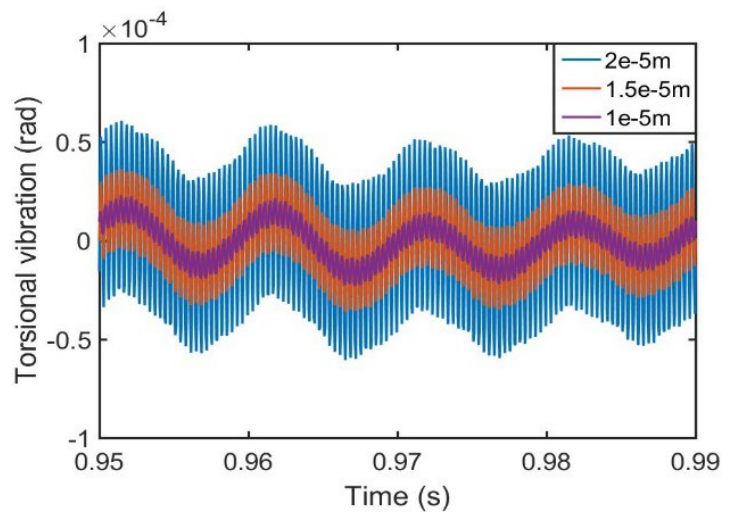

(b) Torsional vibration

Fig. 23 Vibration response of node 4 in gear 1 with various transmission error amplitudes

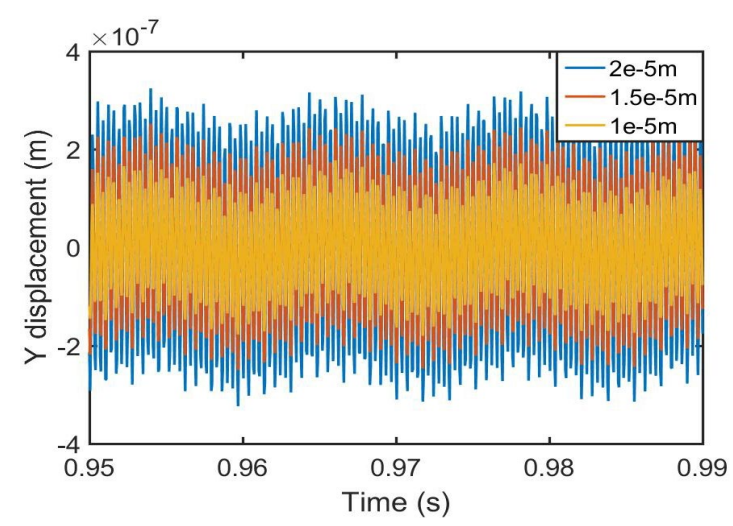

(a) Lateral vibration

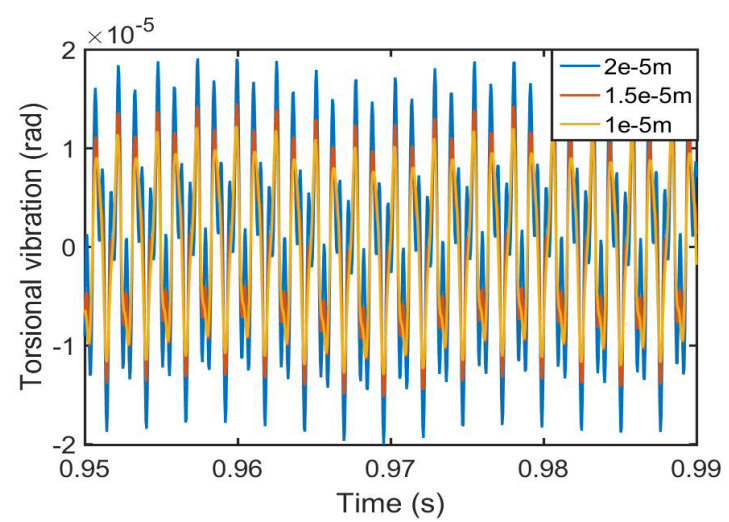

(b) Torsional vibration

Fig. 24 Vibration response of node 13 in the oblique tail shaft with various transmission error amplitudes 


\section{Conclusions}

In this study, the coupled dynamic model of the intermediate and tail gearboxes' system was proposed by the finite element and lumped mass method. Then, the dynamic equations were solved by Newmark numerical algorithm. On this basis, the effects of laminated membrane coupling, eccentricity, tail rotor excitation, oblique tail shaft's length and transmission error amplitude on the system dynamics were investigated, and the following conclusions were obtained.

(1) The effect of laminated membrane coupling on the coupled system's vibration response was prominent; meanwhile, the vibration response of the system was less fluctuant on the position that was not isolated by the laminated membrane coupling. Additionally, the laminated membrane coupling could reduce the mutual effect between gear pairs. So, the laminated membrane coupling should not be omitted in the dynamic model.

(2) The lateral vibration caused by the gear eccentricity exerted an impact on the oblique tail shaft's torsional vibration because of bending-torsional coupled effect; meanwhile, gear eccentricity had a greater influence on the oblique tail shaft's torsional vibration compared with the transverse vibration. Moreover, the coupled effect between the eccentricities of gear pairs mainly affected the torsional vibration, but not the transverse vibration in the low-speed range.

(3) The tail rotor excitation exerted an impact on the torsional and lateral vibration of the system, in which it had a more prominent effect on the system's torsional vibration, and the influence gradually decreased from the output shaft to the input shaft.

(4) With the changing length of the oblique tail shaft, the oblique tail shaft's bending and torsional vibration varied intensely. Therefore, the length of the connecting shaft should be chosen reasonably.

(5) As the transmission error amplitude increases, both the lateral vibration and torsional vibration of the gear pair rise. Besides, due to the flexural-torsional coupled effect, the effect on the vibration characteristics of the of other parts of the system also exhibited the corresponding trend, but the variation degree was less than the excitation source.

\section{Acknowledgements}

This research is supported by National Key Research and Development Program of China (No. 2018YFB2001300), National Natural Science Foundation of China (No. 51775265).

\section{References}

[1] Wang SM, Shen YW and Dong HJ. Nonlinear dynamical characteristics of a spiral bevel gear system with backlash and time-varying stiffness. Chin J Mech Eng 2003,39:28-31.

[2] Fan L, Wang SP, Wang XJ, et al. Nonlinear dynamic modeling of a helicopter planetary gear train for carrier plate crack fault diagnosis. Chinese J Aeronaut 2016,29(3):675-687.

[3] Choi ST and Mau SY. Dynamic analysis of geared rotor-bearing systems by the transfer matrix method. J Mech Design 2001,123:562-568.

[4] Fan YS, Wang SM, Yang Z, et al. Vibration analysis method for multi-rotor system geared by angular spiral bevel gears. J Harbin Inst Technol 2011,43:111-116.

[5] Neriya, SV, Bhat RB and Sankar TS. The coupled torsional-flexural vibration of a geared shaft system using finite element method. Shock Vib Bulletin 1985,55:13-25.

[6] Wu JS and Yang IH. Computer method for torsion-and-flexure-coupled forced vibration of shafting system with damping. J Sound Vib 1995,180:417-435. 
[7] Kahraman A, Nevzat Ozguven H, Houser DR, et al. Dynamic analysis of geared rotors by finite elements. J Mech Design 1992,114:1-20.

[8] Kubur M and Kahraman A. Dynamic analysis of a multi-shaft helical gear transmission by finite elements: model and experiment. J Vib Acoust 2004,126:398-406.

[9] Hong J, Yu PC, Zhang DY, et al. Modal characteristics analysis for a flexible rotor with nonsmooth constraint due to intermittent rub-impact. Chinese J Aeronaut 2018,31(3):498-513.

[10] Li M and Hu HY. Dynamic analysis of a spiral bevel-geared rotor-bearing system. J Sound Vib 2003,259:605-624.

[11] Yavuz SD, Saribay ZB and Cigeroglu E. Nonlinear time-varying dynamic analysis of a spiral bevel geared system. Nonlinear Dynam 2018,92:1901-1919.

[12] Zhu HM, Chen WF, Zhu RP, et al. Modelling and dynamic analysis of the spiral bevel gearshaft-bearing-gearbox coupling system. Mathe Probl Eng 2019,2019:1-16.

[13] Wang Q and Zhang YD. Coupled analysis based dynamic response of two-stage helical gear transmission system. J Vibr Shock 2012,10:87-91.

[14] Jian L and Parker RG. Mesh stiffness variation instabilities in two-stage gear systems. J Vib Acoust 2002,124:68-76.

[15] Al-shyyaba A and Kahraman A. Non-linear dynamic analysis of a multi-mesh gear train using multi-term harmonic balance method: sub-harmonic motions. J Sound Vib 2005,279:417-451.

[16] Walha L, Fakhfakh T and Haddar M. Nonlinear dynamics of a two-stage gear system with mesh stiffness fluctuation, bearing flexibility and backlash. Mech Mach Theory 2009,44:1058-1069.

[17] Rao Z, Zhou CY, Deng ZH, et al. Nonlinear torsional instabilities in two-stage gear systems with flexible shafts. Int J Mech Sci 2014,82:60-66.

[18] Yassine D, Ahmed H, Lassaad W, et al. Effects of gear mesh fluctuation and defaults on the dynamic behavior of two-stage straight bevel system. Mech Mach Theory 2014,82:71-86.

[19] Li W, Sun JD, Yu JP. Analysis of dynamic characteristics of a multi-stage gear transmission system. J Vib Control 2019,25:1653-1662.

[20] Tan JJ, Zhu CC, Song CS, et al. Effects of flexibility and suspension configuration of main shaft on dynamic characteristics of wind turbine drivetrain. Chin J Mech Eng 2019,32:1-15.

[21] Lin TJ, Cao H, Tan ZR, et al. Dynamic performance optimization of coupled system for fourstage planetary gear reducer. $J$ Mechl Eng 2018,54:161-171.

[22] Liu W, Shuai ZJ, Guo YB, et al. Modal properties of a two-stage planetary gear system with sliding friction and elastic continuum ring gear. Mech Mach Theory 2019,135:251-270.

[23] Yan HY, Chen SY, Tang JY. Rocking vibration and dynamic characteristics of a two-stage spur and bevel gear transmitting system. P I Mech Eng C-J Mech 2016,231:4528-4547.

[24] Mo S, Zhang T, Jin GG, et al. Analytical Investigation on Load Sharing Characteristics of Herringbone Planetary Gear Train with Flexible Support and Floating Sun Gear. Mech Mach Theory 2020, 144 (2):1-27.

[25] Mo S, Yue ZX, Feng ZY, et al. Analytical investigation on load-sharing characteristics for multi-power face gear split flow system. P I Mech Eng C-J Mech 2020, 234(2):676-692.

[26] Mo S, Gong JB, Jin GG, et al. Precise Modeling of Complex Tooth Surface Microtopography and Multi-degree of Freedom Nonlinear Friction Dynamics for High Performance Face Gear [J]. Sci Progress-UK 2019, 103(1):1-28.

[27] Hutchinson JR. Shear coefficients for Timoshenko beam theory. J Appl Mech-T ASME 2001,68:959-960. 
[28] Friswell MI, Penny JET, Garvey SD, et al. Dynamics of rotating machines. London: Cambridge University Press, 2010.

[29] Huebner KH, Dewhirst DL and Smith DE. The finite element method for engineers. New York: Wiley, 2001.

[30] Kasuba R and Evans JW. An extended model for determing dynamic loads in spur gearing. $J$ Mech Design 1981,103:398-409.

[31] Wang KL and Cheng HS. A numerical solution to the dynamic load, film thickness, and surface temperatures in spur gear, part I analysis. J Mech Design 1977,103:177-187.

[32] Wei J, Zhang A, Qin D, et al. A coupling dynamics analysis method for a multistage planetary gear system. Mech Mach Theory 2017,110:27-49.

[33] Jin YL, Lu K, Huang CX, et al. Nonlinear dynamic analysis of a complex dual rotor-bearing system based on a novel model reduction method. Appl Math Model 2019,75:553-571.

[34] Li CF, Zhou SH, Liu J, et al. Coupled lateral-torsional-axial vibrations of a helical gear-rotorbearing system. Acta Mech Sinica-Prc 2014,30:746-761.

[35] Zhou SH, Song GQ, Sun MN, et al. Nonlinear dynamic response analysis on gear-rotor-bearing transmission system. J Vib Control 2018,24:1632-1651.

[36] Zhu ZB, Zhu RP and Bao HY. Torsional vibration characteristics analyzing and modeling for helicopter tail drive system. J Aerosp Power 2013,28:432-438. 